\title{
Review Article "Spotlight on Ultrasonography in the Diagnosis of Peripheral Nerve Disease: The Evidence to Date"
}

\author{
Andrew Hannaford' \\ Steve Vucic \\ Matthew C Kiernan (iD ${ }^{2}$ \\ Neil G Simon ${ }^{3}$ \\ 'Westmead Clinical School, Westmead \\ Hospital, University of Sydney, Sydney, \\ Australia; ${ }^{2}$ Brain and Mind Centre, \\ University of Sydney, University of Sydney \\ and Department of Neurology, Royal \\ Prince Alfred Hospital, Sydney, Australia; \\ ${ }^{3}$ Northern Beaches Clinical School, \\ Macquarie University, Sydney, Australia
}

\begin{abstract}
Neuromuscular ultrasound is rapidly becoming incorporated into clinical practice as a standard tool in the assessment of peripheral nerve diseases. Ultrasound complements clinical phenotyping and electrodiagnostic evaluation, providing critical structural anatomical information to enhance diagnosis and identify structural pathology. This review article examines the evidence supporting neuromuscular ultrasound in the diagnosis of compressive mononeuropathies, traumatic nerve injury, generalised peripheral neuropathy and motor neuron disease. Extending the sonographic evaluation of nerves beyond simple morphological measurements has the potential to improve diagnostics in peripheral neuropathy, as well as advancing the understanding of pathological mechanisms, which in turn will promote precise therapies and improve therapeutic outcomes.
\end{abstract}

Keywords: neuromuscular ultrasound, peripheral neuropathy, entrapment neuropathy, CIDP, hereditary neuropathy, amyotrophic lateral sclerosis

\section{Introduction}

Entrapment mononeuropathies are common and contribute to considerable morbidity in the community. The most common entrapment is carpal tunnel syndrome, with an estimated incidence of 197 per 100,000 women, ${ }^{1,2}$ and much higher rates among employees in certain industries (eg, up to $42 \%$ prevalence in poultry workers). ${ }^{3,4}$ Early diagnosis is essential in entrapment mononeuropathy, to limit nerve injury and associated morbidity. Unfortunately, electrodiagnostic studies (EDX) are frequently non-localising in entrapment neuropathy, and this is the most frequent indication for nerve ultrasound in clinical practice. ${ }^{5}$ In addition, a significant proportion of EDX are non-diagnostic, between $10 \%$ and $25 \%$ in CTS for instance, depending on the severity of presentation and EDX protocol used. ${ }^{6,7}$

Separately, peripheral neuropathy $(\mathrm{PN})$ represents a major cause of morbidity globally, ${ }^{8}$ and it's prevalence is increasing. This has been attributed to the ageing population, an increased prevalence of diabetes and use of neurotoxic drugs such as chemotherapeutics and antiretrovirals. $^{9-14}$ The assessment of PN has traditionally relied on neurological assessment, close review of comorbidities and EDX testing. EDX enables neuropathy to be diagnosed, providing information on the pattern of involvement, severity, distinction between axonal and demyelinating pathologies, as well as allowing prognostication and monitoring. ${ }^{15}$ The clinical and EDX
Correspondence: Neil G Simon

Suite 6a, Northern Beaches Hospital, 105 Frenchs Forest Road W, Frenchs Forest, NSW, 2086, Australia

Tel +6I 299822270

Fax+6I 299817880

Email neil@nbneuro.com.au 
assessment has several limitations however, including a lack of precise anatomical information, ${ }^{15}$ difficulty diagnosing proximal demyelinating $\mathrm{PN},{ }^{16}$ and difficulty in distinguishing hereditary from acquired demyelinating PN. ${ }^{17,18}$ Consequently, there is a need for newer techniques to better diagnose and monitor patients with PN.

Ultrasound using modern, high-frequency probes and image processing provides excellent visualisation of the peripheral nerve, with good spatial resolution and the ability to assess vascularisation with power Doppler. Ultrasound has the further advantage of being able to assess the entire nerve course in real time, whilst being quick, painless, non-invasive, free of radiation and relatively cheap. Ultrasound therefore provides the ideal tool for assessing PN, entrapment mononeuropathy and complements the clinical and EDX assessment. Given the rapid uptake of ultrasound by clinicians, the present review is designed as a practical resource to promote an understanding of the basics of peripheral nerve ultrasound as well as current and emerging applications of ultrasound in the diagnosis of neurological disease.

\section{Ultrasound Physics as Relevant to Nerve and Muscle}

An ultrasound system uses a transducer to convert electrical current into ultrasound waves via the piezoelectric effect. These waves travel through tissue and are either reflected, refracted, scattered, or absorbed. The amount of resistance an ultrasound beam experiences as it travels through a tissue is referred to as acoustic impedance and is dependent on tissue density. The degree of ultrasound reflection is dependent on the relative differences in tissue densities at a tissue interface, as well as the angle of insonation. Reflected waves are recorded by the transducer and converted into electrical energy which is used to generate our image. The brightness of this image is labelled echointensity (EI) and is proportional to the amount of reflection. This signal is amplified (gain), which can be adjusted. Anisotropy is the loss of echogenicity when an ultrasound beam is not perpendicular to the structure imaged and can be exploited to distinguish peripheral nerves (low anisotropy) from adjacent structures such as tendons (high anisotropy).

The ultrasound image resolution is determined largely by the frequency of the waves, recorded in megahertz $(\mathrm{MHz})$. Higher frequencies allow for greater image resolution, and frequencies greater than $12 \mathrm{MHz}$ are typically utilised for peripheral nerve imaging. In contrast, higher frequencies undergo greater attenuation at increasing depths, and therefore lower frequency ultrasound with better penetration is preferable when imaging deeper structures such as muscle. Consequently, ultrasound imaging is a trade-off between resolution and penetrance, which is achieved in neuromuscular ultrasound by using a transducer with a range of frequencies, for example, 18-6 MHz. Linear array transducers are typically used in neuromuscular diagnosis, providing a narrower field of view but better resolution at the edges of an image than curvilinear transducers. A smaller footprint probe is sometimes desirable when imaging structures where only limited contact between a probe and the body surface is possible, for instance the hands and feet.

\section{Ultrasound Changes in Neuropathy Normal Nerves}

The appearance of peripheral nerves on ultrasound correlates with the microscopic and macroscopic anatomy. ${ }^{19}$ When viewed longitudinally nerves appear as linear hypoechoic fascicles surrounded by hyperechoic perineurial connective tissue, both enclosed by the bright epineurial connective tissue layer (Figure 1). In cross section, nerves take on a "honeycomb" appearance of rounded hypoechoic fascicles surrounded by hyperechoic connective tissue (Figure 1). The size and fascicular pattern of healthy nerves can vary depending on location. More proximal nerve segments are typically larger in cross-sectional area (CSA) with fewer or no fascicles, meaning they appear more hypoechoic. This is the result of densely packed fascicles with less connective tissue. ${ }^{20}$ This process also occurs at fibro-osseous boundaries, for instance the ulnar nerve at the level of the medial epicondyle also appears relatively more hypoechoic even in normal limbs ${ }^{21}$ (Figure 2D).

When differentiating nerves from other structures the following key features can be utilised. Firstly, nerves are surrounded by a hyperechoic rim due to epineurial connective tissue. Secondly, they are more anisotropic than muscle and tendons, meaning tilting the transducer will markedly change the echointensity of these other structures when compared to nerves. Thirdly, unlike blood vessels they are noncompressible, with no pulsatile movement or Doppler flow.

\section{Abnormal Nerves}

There are several characteristic sonographic features in peripheral nerve injury, including changes in nerve size, 


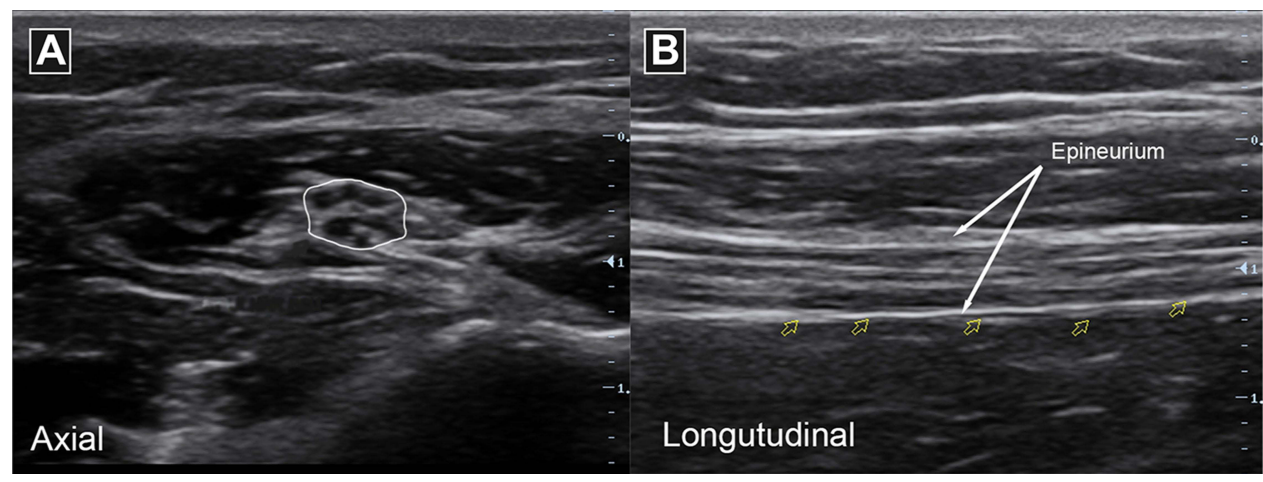

Figure I Ultrasound appearance of normal nerves. Ulnar nerve imaged in axial/cross-sectional view with "honeycomb" pattern (A) and longitudinal view with "tram track" pattern (B).

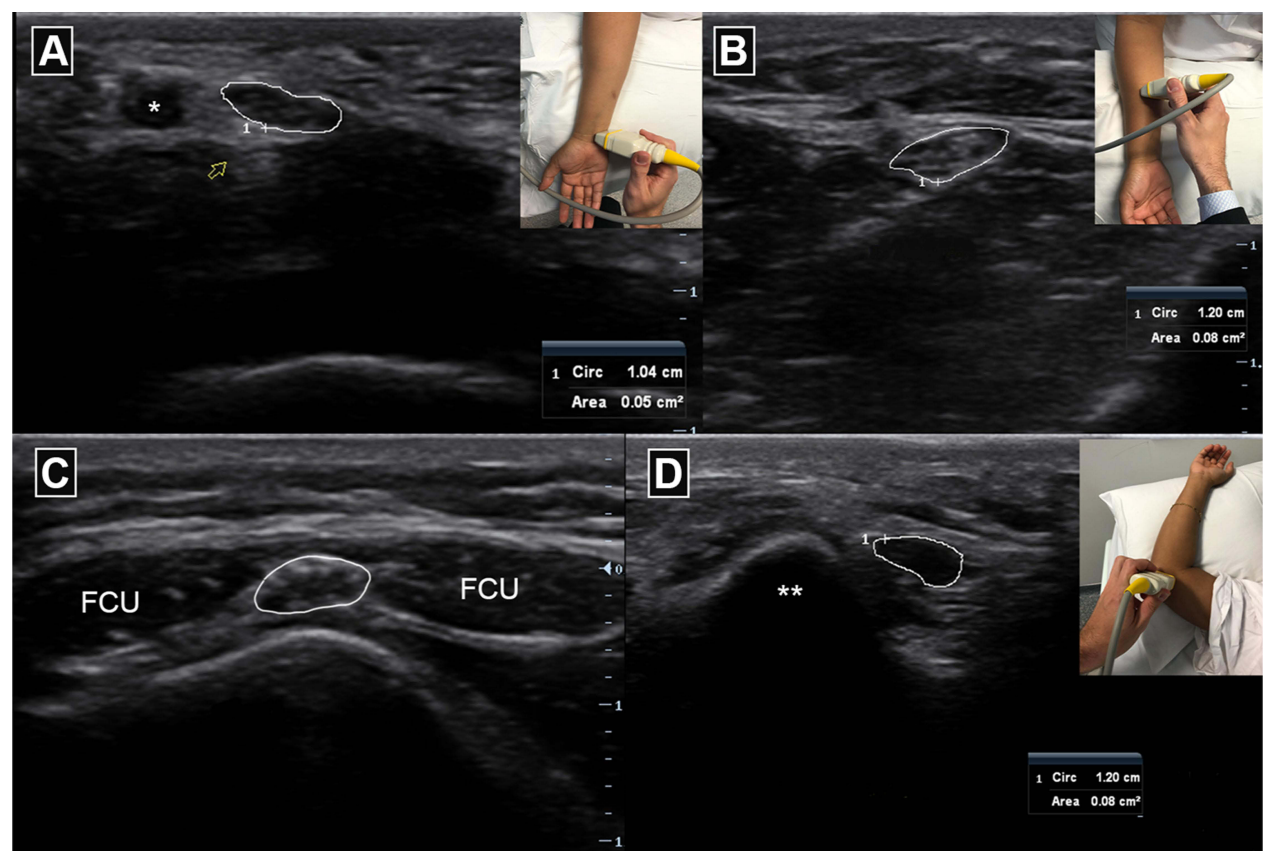

Figure 2 Normal ulnar nerve and ulnar artery (artery denoted ${ }^{*}$ ) in cross section at the wrist $(\mathbf{A})$ in Guyon's canal. Ulnar nerve in cross section in the forearm (B), cubital tunnel between two heads of flexor carpi ulnaris (FCU) muscle (C) and between the medial epicondyle (**) and olecranon at the elbow (D).

echointensity, fascicle dimensions, epineurial boundaries and Doppler signal. Peripheral nerve size increases focally with entrapment and more diffusely in some patients with PN. The cross-sectional area (CSA), measured by tracing inside the hyperechoic epineurium, has a high inter and intraobserver reliability and is highly reproducible. ${ }^{22}$ The CSA has been widely used to quantify PN, by reference to established normal values for several key peripheral nerves and the brachial plexus. ${ }^{23-26}$ It is important to adjust CSA for normal variability seen across age, sex, height, and BMI. ${ }^{23,24}$

Echointensity is typically reduced in nerve injury and is usually assessed qualitatively and is usually associated with loss of the normal fascicular architecture described above. Nerve echogenicity can be measured quantitatively using mean gray-scale analysis. ${ }^{21,27,28}$ Quantitative measures are specific to the individual ultrasound machine used to establish the normative data, limiting their broader application, unless values are normalized using standardized phantoms.

Improvements in ultrasound technology has facilitated measurement of individual nerve fascicles, ${ }^{29}$ for instance ultra-high frequency ultrasound can identify increased fascicular diameter in immune-mediated PN. ${ }^{30}$ Fascicular architecture varies from person to person, nerve to nerve and from one anatomical location to another, and there is more work needed to characterise this metric in health and disease. 
The Doppler effect is a change in ultrasound frequency reflected from an object, such as a red blood cell, moving toward or away from the transducer. This can be used to demonstrate changes in vascularity of peripheral nerves and surrounding structures. Normal nerve does not have any detectable blood flow. Hence, the presence of Doppler flow is abnormal in peripheral nerves and indicates hypervascularity, which has been described in compressive and inflammatory and some axonal neuropathies. ${ }^{31-33}$

Elastography is a technique used to determine the elasticity of tissue. This is in the form of either strain elastography, in which tissue displacement from extrinsic compression or ambient tissue oscillations is used, or shear wave elastography (SWE), produced by acoustic radiation force impulses generated by the ultrasound probe. Peripheral nerve injury involves the destruction of myelin, which is more compliant, and a proliferation of stiff connective tissue. $^{34}$ This results in increased stiffness on elastography. There are now several studies supporting the role of both strain and shear wave elastography in diagnosing carpal tunnel syndrome, ulnar neuropathy at the elbow, diabetic PN and even optic neuropathy. ${ }^{35}$ Further research is ongoing to assess the ability of elastography to diagnose nerve injury in preclinical neuropathy, and to evaluate elastography as a monitoring tool for longitudinal assessment.

\section{Compressive Mononeuropathies}

Peripheral nerve compression results in nerve enlargement proximal /or distal to the entrapment site on crosssectional imaging and can appear as an hourglass configuration on longitudinal views (Figure 3). ${ }^{5,36,37}$ The entrapped nerve may also appear flattened, hypoechoic, immobile and hypervascular. ${ }^{37-39}$ Importantly, up to $42 \%$ of mononeuropathy cases studied with ultrasound detect a pathology that alters diagnosis or management, for instance nerve strictures, ganglion cysts or other intraneural or extraneural lesions. ${ }^{40}$

Interestingly, a "Sonographic Tinel" sign may be present, with clinical symptoms elicited by mechanical pressure from the ultrasound probe at a compression site. Of further interest, chronic nerve compression may result in "neurogenic" changes to the muscle supplied, such as hyperechogenic and eventually atrophied muscle with fasciculations. The sonographic findings for specific mononeuropathies are summarised below and in Table 1.

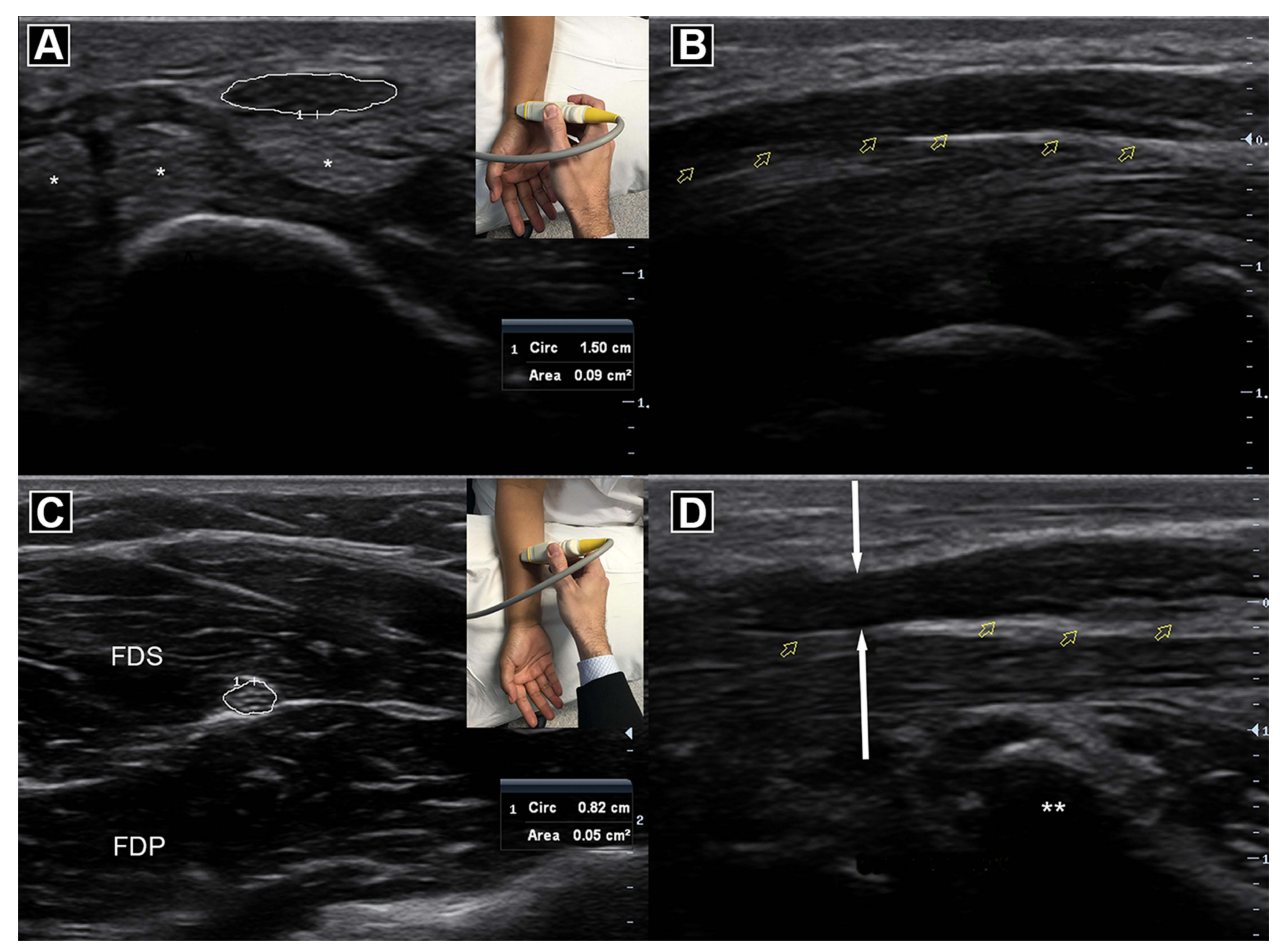

Figure 3 Normal median nerve and flexor tendons $\left(^{*}\right)$ in cross section $(\mathbf{A})$ and longitudinal view (B). Normal median nerve in the forearm (C) superficial to flexor digitorum profundus (FDP) and deep to flexor digitorum superficialis (FDS) muscles. Abnormal median nerve at the wrist (D) with hourglass constriction (white arrows) with swelling proximally at the carpal tunnel entrance $(* *)$. 
Table I Diagnostic Sonographic Findings in Compressive Mononeuropathies

\begin{tabular}{|c|c|c|}
\hline & Sonographic Findings & Diagnostic Utility \\
\hline \multirow[t]{9}{*}{ Carpal tunnel syndrome } & CSA distal wrist crease $>8.5-10 \mathrm{~mm}^{2,39}$ & $\begin{array}{l}\text { Sensitivity } 65-97 \% \text { Specificity } 73-98 \% \\
\text { PPV } 79-97 \%\end{array}$ \\
\hline & WFR $>1.4^{252}$ & Sensitivity $100 \%$ Specificity* \\
\hline & If EDX normal > $14 \mathrm{~mm}^{2}$ WFR $>1.8^{5}$ & \\
\hline & Hypoechoic proximal to compression $39,253,254$ & Sensitivity 100\% Specificity* \\
\hline & $\begin{array}{l}\text { Loss of fascicular architecture }{ }^{255} \\
\text { Shear wave elastography: increased stiffness }{ }^{34,256-261}\end{array}$ & $\begin{array}{l}\text { Sensitivity } 95 \% \text {, Specificity } 71 \%, \text { PPV } \\
94 \%\end{array}$ \\
\hline & Shear wave elastography: increased stiffness ${ }^{34,256-261}$ & $\begin{array}{l}\text { Sensitivity } 65-100 \% \text {, Specificity } 45- \\
100 \%\end{array}$ \\
\hline & $\begin{array}{l}\text { Increased vascularity }{ }^{37} \\
\text { Reduced nerve mobility }\end{array}$ & \\
\hline & Reduced nerve mobility ${ }^{262,263}$ & \\
\hline & $\begin{array}{l}\text { Anatomical anomalies: Bifid median nerve, }{ }^{264} \text { persistent median artery, }{ }^{264} \\
\text { anomalous muscle }\end{array}$ & \\
\hline \multirow{5}{*}{$\begin{array}{l}\text { Ulnar neuropathy at the } \\
\text { elbow }\end{array}$} & Maximum CSA $>8.3-11 \mathrm{~mm}$ & Sensitivity $88-100 \%$ Specificity 7 I-97\% \\
\hline & Swelling ratios (CSA elbow vs upper arm) $>1.5^{266}$ & Sensitivity $74-100 \%$ Specificity $96.7 \%$ \\
\hline & Shear wave elastography: increased stiffness ${ }^{267,268}$ & Sensitivity $100 \%$, Specificity $100 \%$ \\
\hline & Loss of internal fascicular structure ${ }^{269}$ & \\
\hline & $\begin{array}{l}\text { Increased vascularity }{ }^{57} \text { in } 15 \% \text {. Correlates with severity and axonal } \\
\text { damage. }\end{array}$ & \\
\hline \multirow{2}{*}{$\begin{array}{l}\text { Radial neuropathy at the } \\
\text { spiral groove }\end{array}$} & $\mathrm{CSA}>5.75 \mathrm{~mm}^{2} 270$ & Sensitivity $52.9 \%$, specificity $90 \%$ \\
\hline & CSA symptomatic minus asymptomatic side $>1.75 \mathrm{~mm}^{2} 270$ & Sensitivity $58.8 \%$, specificity $100 \%$ \\
\hline \multirow{4}{*}{$\begin{array}{l}\text { Fibular neuropathy at the } \\
\text { knee }\end{array}$} & CSA fibular head $>11.7 \mathrm{~mm}^{2} 271$ & Sensitivity $85.0 \%$, Specificity $90.0 \%$ \\
\hline & CSA symptomatic minus asymptomatic side $>1.70 \mathrm{~mm}^{2}$ & Sensitivity $83.3 \%$, Specificity $97.0 \%$ \\
\hline & Fibular head to popliteal fossa CSA ratio > I.II & Sensitivity $47.1 \%$, Specificity $93.3 \%$ \\
\hline & Hypoechoic at fibular head on quantitative ultrasound ${ }^{83}$ & Sensitivity $82-84 \%$, Specificity $83-95 \%$ \\
\hline \multirow[t]{2}{*}{ Tarsal tunnel syndrome } & CSA tarsal tunnel $>15-19 \mathrm{~mm}^{2} 272,273$ & Sensitivity $61-74 \%$ Specificity $100 \%$ \\
\hline & Within tunnel-to-proximal tunnel CSA ratiol ${ }^{272}$ & \\
\hline
\end{tabular}

Abbreviations: CSA, cross sectional area; WFR, wrist to forearm ratio measured at distal wrist crease and $12 \mathrm{~cm}$ proximal; EDX, electrodiagnostic studies; Specificity*, specificity could not be calculated due to the design of the study, as all patients imaged had the disease.

Median Neuropathy at the Wrist (Carpal Tunnel Syndrome)

The median nerve is optimally studied with the patient seated or lying with the palm facing upward. Imaging can begin at the distal wrist crease, with a cross-sectional view of the median nerve at the entry to the carpal tunnel. The nerve can then be traced proximally as it dives between the flexor digitorum superficialis and profundus in the forearm, and then between the two heads of the pronator teres (another potential site of entrapment). ${ }^{41,42}$ At the elbow, it runs with the brachial artery, and it can be traced with the artery up to the axilla.

Carpal tunnel syndrome (CTS) results in increased median nerve CSA at the wrist (Figure 3). The ratio of CSA between the wrist and forearm $(12 \mathrm{~cm}$ proximal to the distal wrist crease), known as "wrist to forearm ratio" (WFR) will also be increased (Table 1). The median nerve may also be swollen distally at the carpal tunnel outlet, 
and scanning this region increases the diagnostic sensitivity by $15 \%-20 \%{ }^{43,44}$ The presence of an immobile, hypoechoic or hypervascular median nerve at the wrist also aids in diagnosis. ${ }^{39}$ There are several clinical and EDX mimics for CTS, such as benign tumours (neuroma, schwannoma, hamartomas), ganglion cysts, thrombosed vessels or tenosynovitis. ${ }^{45}$ These are easily diagnosed with ultrasound. ${ }^{45,46}$ A bifid median nerve can also be identified, which is more prevalent in patients with CTS. ${ }^{47}$ Ultrasound is useful to assess persistent symptoms post-surgical carpal tunnel release, where it can detect a compressive post-operative scar, a residual anatomical constriction point suggesting incomplete release or an alternative cause for neuropathy. ${ }^{48}$

In addition, ultrasound can localise a proximal median nerve injury and may help establish a cause, such as entrapment by the ligament of Struther's, ${ }^{49}$ pronator teres muscle, ${ }^{50}$ or an accessory palmaris longus muscle, ${ }^{51}$ as well as vascular pathology ${ }^{52}$ and iatrogenic injury. ${ }^{53}$

\section{Ulnar Nerve (Cubital Tunnel)}

The ulnar nerve is ideally studied with the elbow flexed at 90 degrees, palm facing upwards and the patient either seated or supine. The Ulnar nerve can be easily located at the elbow in the groove between the olecranon and the medial epicondyle of the humerus (Figure 2C). The nerve can be traced proximally as it runs between the biceps brachii and medial head of triceps brachii en route to join the axillary artery. The nerve can then be traced from the elbow distally as it travels between the two heads of the flexor carpi ulnaris muscle (forming the cubital tunnel) (Figure 2C), before travelling between the flexor digitorum profundus and superficialis as it approaches the ulnar artery (Figure 2B). The ulnar nerve together with the ulnar artery enter the hand superficially via the guyon's canal (Figure 2A).

Approximately $76 \%$ of ulnar neuropathies are localised to the olecranon groove ${ }^{54}$ and are typically caused by extrinsic compression or stretch of the nerve resulting in focal demyelination. Focal increase in the ulnar nerve CSA at or above the olecranon is diagnostic. ${ }^{55}$ The next most common site for injury is at the cubital tunnel due to ulnar nerve entrapment, referred to as "cubital tunnel syndrome". Ultrasound demonstrating focal nerve constriction at the entry to the tunnel with proximal swelling is diagnostic. Longitudinal views can aid in localising compression. Both the degree of swelling and hypervascularity are markers of severity ${ }^{56}$ and axonal loss. ${ }^{57,58}$ It is important to differentiate cubital tunnel entrapment from compression in the olecranon groove because the former is amenable to surgical release. ${ }^{59}$ Less common aetiology of ulnar nerve injury can also be identified with ultrasound, including Struthers arcade compression in the upper arm, ${ }^{60}$ ganglion at the elbow, benign tumours, abscess or anomalous muscles (anconeus epitrochlearis). ${ }^{55}$ Dynamic ultrasound can also detect a subluxing ulnar nerve, which refers to the migration of the ulnar nerve to the medial epicondyle tip with elbow flexion. Studies assessing the causative role of this abnormality in ulnar neuropathy are conflicting. ${ }^{61-63}$ An elegant study by Omejec et al demonstrated higher rates of ulnar nerve subluxation in patients without a clinical neuropathy, especially those with subclinical ulnar nerve changes on EDX. ${ }^{64}$

A common dilemma when assessing ulnar neuropathy electrodiagnostically is the inability to localise the dysfunction, and between $14 \%$ and $25 \%$ of EDX studies are "non-localising" ${ }^{65,66}$ Importantly, the majority of these electrodiagnostically "non-localising" ulnar neuropathies can be localised with ultrasound. ${ }^{65,66}$ In addition, ultrasound can readily diagnose ulnar nerve injury at Guyon's canal for example due to cycling-related wrist compression, ${ }^{67}$ intraneural ganglion cyst ${ }^{68}$ or ulnar artery thrombosis. ${ }^{69}$

\section{Radial Neuropathy at the Spiral Groove}

The radial nerve is best imaged with the elbow flexed and the dorsal upper arm directed toward the examiner, so that the posterior course of the nerve above the elbow can be easily traced. The nerve is readily identified in the lateral antecubital fossa, lying above the brachialis and beneath the brachioradialis muscles (Figure 4A). At this location, the nerve starts to divide into the superficial and deep branches. The radial nerve can be traced proximally as it wraps behind the humerus. The radial nerve is then followed up to the spiral groove, between the medial and lateral heads of the triceps brachii muscle (Figure 4B). The nerve can be traced from the antecubital fossa distally as it divides. The superficial branch travels laterally, beneath the brachioradialis and next to the radial artery, before perforating the extensor facia in the distal forearm to reach the anatomical snuff box and provides sensation to the dorsolateral hand and dorsal aspect of digits 1-3. The deep branch travels medially and dives through the arcade of Frohse (a fibrous arch extending from supinator muscle to lateral epicondyle) as it pierces the supinator muscle (Figure 4C). The nerve then becomes the posterior 


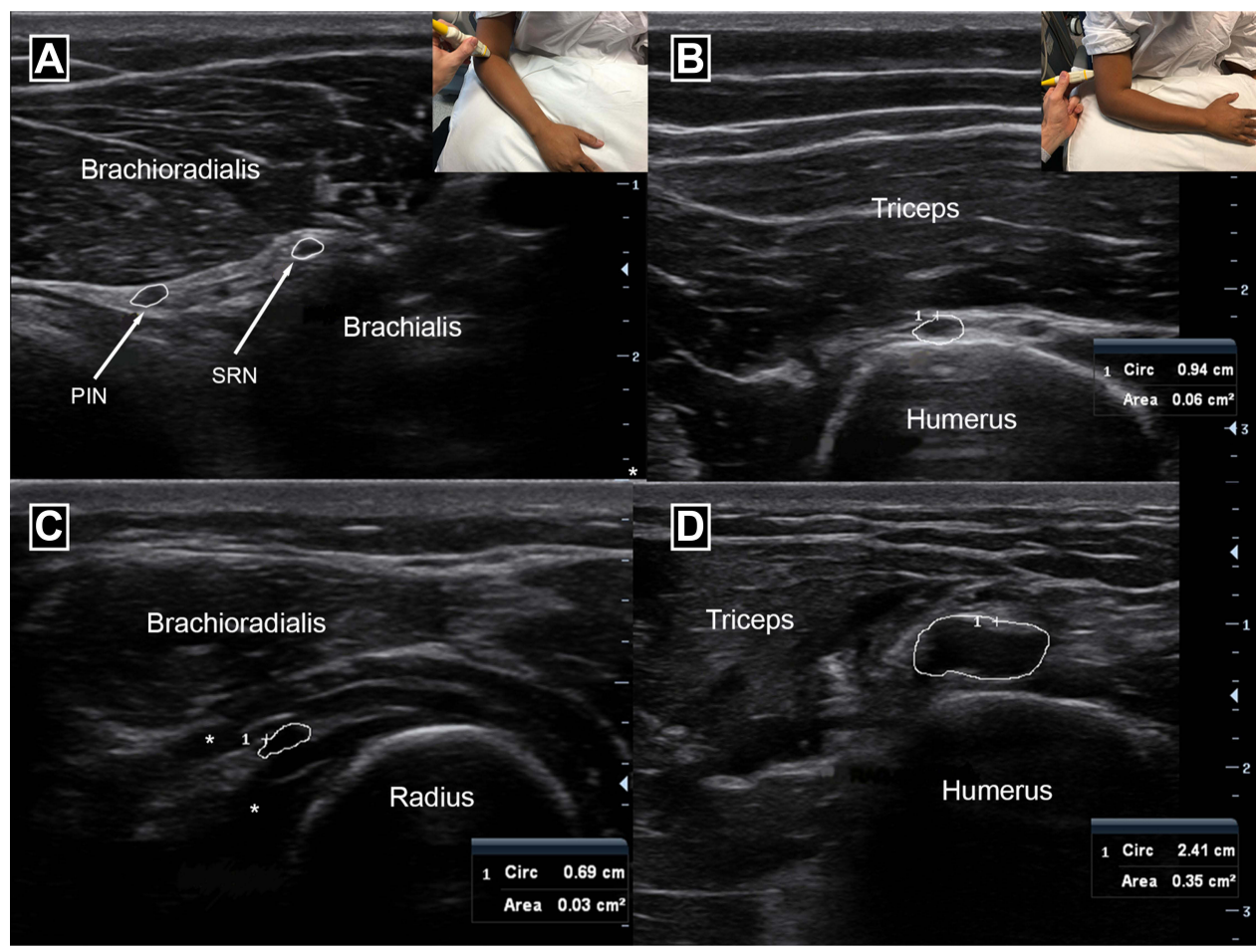

Figure 4 Posterior interosseus nerve (PIN) and Superficial radial nerve (SRN) branches of the radial nerve in the cubital fossa (A). Radial nerve branches deep to brachioradialis and superficial to brachialis muscles. Cross section of normal radial nerve in the spiral groove between the triceps muscle and humerus bone (B). Posterior interosseus nerve travelling between the two heads of supinator muscle $\left(^{*}\right)$ overlying the proximal radius bone (C). Cross section of abnormal enlarged radial nerve in spiral groove with CSA measuring $35 \mathrm{~mm}^{2}$ (D).

interosseus nerve travelling over the interosseus membrane and supplying the extensor compartment of the forearm.

The commonest cause of radial neuropathy is compression at the spiral groove due to extrinsic pressure, known as the "Saturday night palsy" because it may be associated with sleeping awkwardly when sedated. Ultrasound will show focally increased radial nerve CSA in the spiral groove (Figure 4D). This can be based on absolute increase in CSA or side-to-side comparison (Table 1). Swelling in the radial groove also has prognostic value and predicts a worse clinical outcome at 3 months then radial palsy with normal nerve calibre. ${ }^{70}$ Another common cause for proximal radial neuropathy is a humeral shaft fracture. Nerve injury secondary to fracture is readily diagnosed with ultrasound. ${ }^{71}$ The deep motor branch, the posterior interosseus nerve, can be injured at the arcade of Frohse. Causes of this "Posterior Interosseus Syndrome" may be diagnosed with ultrasound including iatrogenic injury, ${ }^{72}$ ganglion cysts, ${ }^{73,74}$ vascular abnormalities, ${ }^{75}$ tumours $^{76}$ and entrapment from other structures. ${ }^{77}$ The superficial radial sensory nerve is susceptible to injury from extrinsic compression, trauma, or mass lesions ${ }^{78-80}$ which may be seen on ultrasound.

\section{Fibular Neuropathy at the Knee}

The fibular nerve can be identified on ultrasound by first imaging the sciatic nerve in the proximal popliteal fossa (Figure 5A) and tracing it distally as it bifurcates into the fibular (lateral) and tibial (medial) nerves (Figure 5B). The common fibular nerve can then be traced around the head of the fibular bone (Figure 5C). An enlarged and hypoechoic nerve at the fibular head support a diagnosis of compression, ${ }^{24,81-83}$ although care must be taken to not image the nerve obliquely at this location. The deep and superficial fibular nerve branches are more difficult to visualise distally due to their small size and depth, although the deep fibular nerve is readily identified in the anterior ankle. The most common cause for fibular nerve injury at the fibular head is stretch or contusion, ${ }^{84}$ often associated with significant weight loss, sustained immobility and excessive leg crossing. ${ }^{85,86}$ However, in one series, as many as $18 \%$ of patients presenting with foot drop, have an intraneural ganglion of the fibular nerve identifiable with ultrasound. ${ }^{87}$ Entrapment of the fibular nerve in the fibular tunnel is a rare cause of fibular neuropathy, ${ }^{88}$ but this can be seen on ultrasound as a focal stricture of the nerve just prior to the fibular (Figure 5). It is critical to 


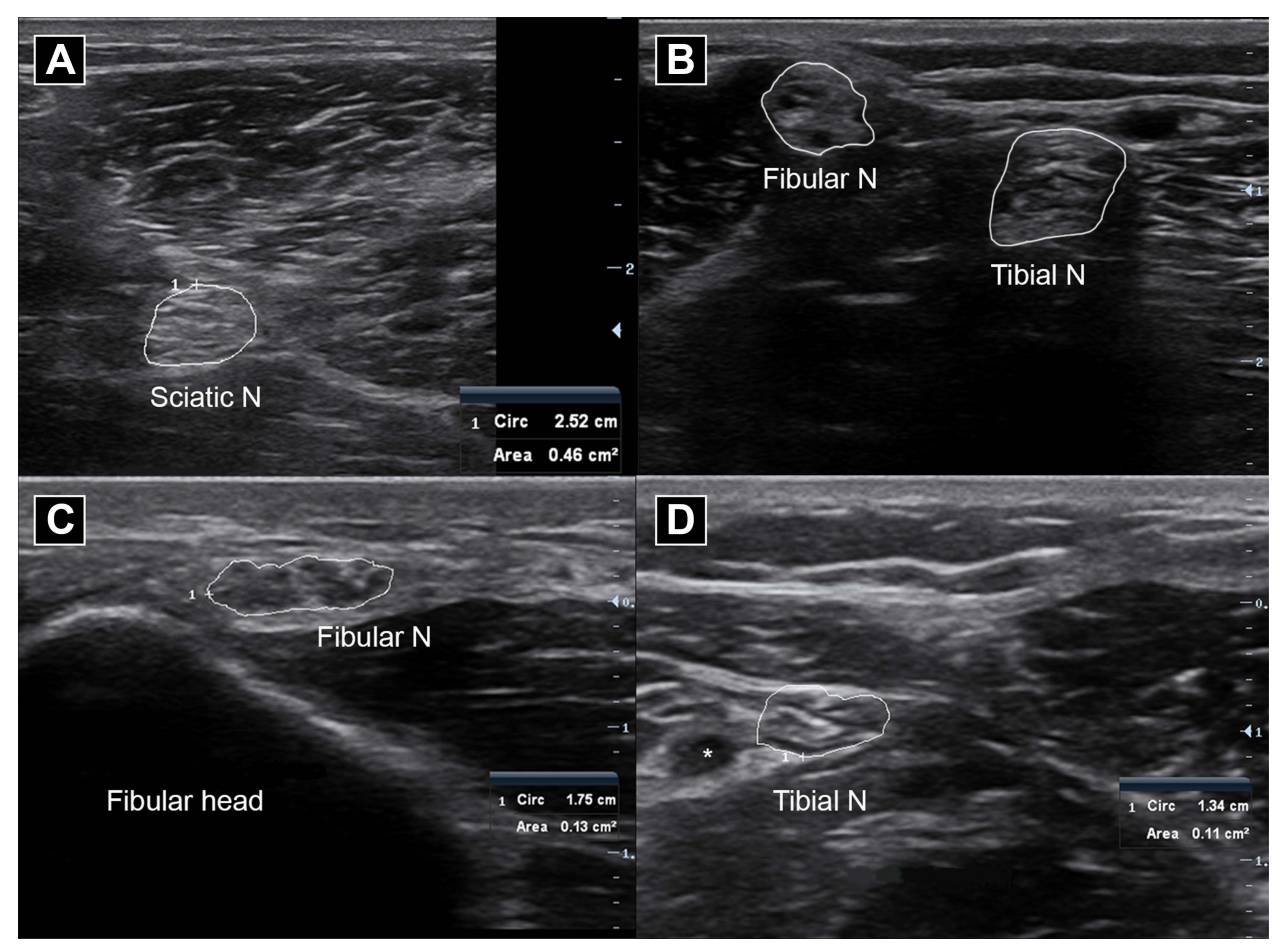

Figure 5 Cross-sectional view of the normal sciatic nerve in the distal thigh (A), fibular and tibial nerves in the popliteal fossa (B), fibular nerve at the fibular head (C) and tibial nerve just above the ankle, ${ }^{*}$ denote the ulnar artery (D).

image patients with fibular neuropathy to exclude entrapment and intraneural ganglion, as these patients require surgical decompression whereas non-operative management is indicated for other causes.

\section{Tibial Neuropathy at the Ankle (Tarsal Tunnel Syndrome)}

The tibial nerve can also be identified in the popliteal fossa (Figure 5B) before it dives between the heads of the gastrocnemius muscle. The patient is usually examined in the prone position. The tibial is more difficult to identify when running deep in the calf due to the overlying gastrocnemius and soleus muscles but the nerve can be imaged distally as it travels behind the medial epicondyle of the ankle, beneath the flexor reticulum (also known as the tarsal tunnel), in the company of the posterior tibial vessels, tibialis posterior, flexor digitorum longus and flexor hallucis longus tendons. The tibial nerve then branches into the medial and lateral plantar nerves to innervate the sole of the foot.

Ultrasound can identify a cause for distal tibial neuropathy in up to $94 \%$ of presentations. ${ }^{89}$ In one series of 81 ultrasound cases the most prevalent causes were varicose plantar veins, static foot disorders, epineurial ganglion cysts, neuropathies, and iatrogenic injuries. Tarsal tunnel syndrome is a rare compressive mononeuropathy which may be diagnosed on ultrasound by demonstrating an enlarged tibial nerve CSA within the tunnel (Table 1). Ultrasound may also detect a cause in proximal tibial neuropathies, such as baker's cyst ${ }^{90}$ or soleus arcade/ sling. ${ }^{91,92}$

\section{Traumatic Peripheral Nerve Injury}

After significant nerve trauma we may see "axonotmesis" with interruption of axons but intact connective tissue which acts to guide axonal regrowth. If severe axonotmesis occurs, axonal regrowth occurs proximal to distal at a rate of $1 \mathrm{~mm}$ per day. Alternatively, nerve trauma may result in "neurotmesis" with interruption of both axon and connective tissue. In this circumstance, axonal regeneration is precluded by scar tissue. ${ }^{93}$ There are several limitations to clinical and EDX evaluation of traumatic peripheral nerve injury. EDX in the acute setting cannot differentiate between a nerve with damaged axons but intact connective tissue and a complete nerve transection. ${ }^{94}$ This is crucial, however, because complete transection can improve with time-critical surgical intervention. In addition, without imaging one cannot identify other specific anatomical lesions that may require surgery, for instance a painful chronic neuroma, ${ }^{95}$ or ongoing nerve 
injury from bone spurs, haematoma, or surgical hardware. $^{96}$

Importantly, ultrasound can assist in diagnosing and localising a traumatic peripheral nerve injury. ${ }^{95,96}$ This is visualised by focal swelling and reduced echogenicity, altered fascicular architecture, discontinuity ${ }^{97}$ or neuroma formation. ${ }^{95}$ In addition, ultrasound allows the detection of muscle hyperintensity and atrophy secondary to nerve trauma, which often precedes other sonographic and EDX changes. ${ }^{98}$ In addition, ultrasound can be used to assess whether surgical intervention is required in the setting of nerve discontinuity, ${ }^{96}$ neuromas ${ }^{99}$ or bony entrapment. ${ }^{100,101}$ It is worth noting that ultrasound will not differentiate between severe axonal injury with and without intact epineurium.

Ultrasound also plays a role in surgical planning, by identifying the exact location and length of nerve injury as well as associated structures. ${ }^{20,96,102}$ Intraoperative highresolution nerve ultrasound monitoring can also be used ${ }^{103}$ as it matches closely with intraoperative neurophysiological and neuropathological findings. Following surgical peripheral nerve repair ${ }^{104}$ ultrasound has a role in identification of partial discontinuity, neuroma formation and compression by overlying scars that may require surgical re-exploration. In a retrospective series of 143 consecutively imaged traumatic peripheral nerve injuries ${ }^{96}$ ultrasound was $90 \%$ sensitive for any nerve injury. The most common abnormalities seen were nerve swelling, followed by neuroma, scar tissue, and discontinuity. Complete nerve transections were infrequent, but readily identified by swollen nerve stumps proximally and distally. The degree of nerve swelling did not correlate with severity of motor dysfunction on EDX.

Thus, ultrasound is an important tool in diagnosing and localising nerve trauma, grading injury, determining the need for surgery and provides useful information in the intra and post-operative setting. In concert with improvements in ultrasound, MRI techniques to visualize the peripheral nervous system such as Diffusion tensor imaging (DTI) have undergone rapid development. DTI with tractography uses water diffusion anisotropy along longitudinal fibre tracts to image nerve pathways. ${ }^{105}$ DTI has the capability to image nerve injury not identified using EDX or standard imaging techniques. ${ }^{93}$ In addition, DTI can identify axonal regeneration following traumatic nerve injury with the potential to guide the need for surgical intervention. ${ }^{106}$

\section{Generalised Peripheral Neuropathies}

Generalised peripheral neuropathy may be associated with changes on nerve ultrasound. The most prominent changes are identified in demyelinating neuropathies where nerve enlargement is characteristic. Axonal neuropathies are perhaps surprisingly only infrequently associated with reduction of nerve size. The role for ultrasound in diagnosing PN is increasing, and it has the potential to streamline diagnostic algorithms, reduce the need for expensive or invasive investigations and even rationalise costly immunomodulatory and genetic therapies. The following section explores the current ultrasound findings in hereditary, immune mediated and axonal PN.

\section{Immune Mediated Polyneuropathy Chronic Inflammatory Demyelinating Polyneuropathy (CIDP)}

CIDP is an immune-mediated process typified by multifocal demyelinating nerve pathology in proximal and distal limbs, leading to weakness, sensory loss and reduced deep tendon

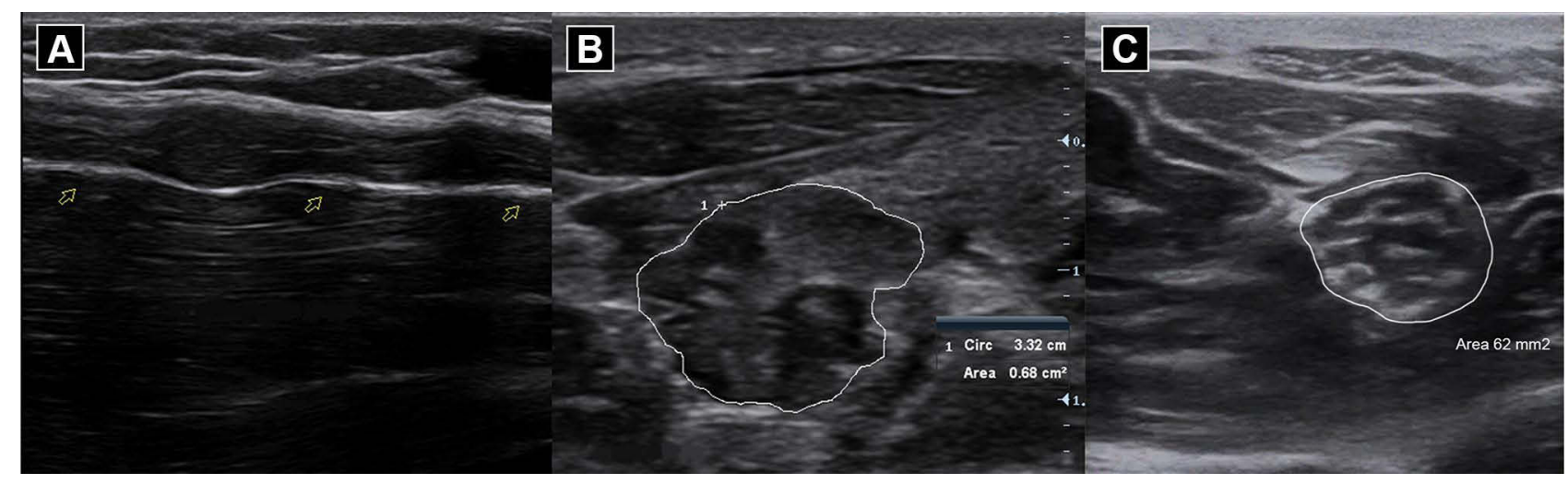

Figure 6 Abnormal median nerve in the forearm in Chronic Inflammatory Demyelinating Polyneuropathy (CIDP), demonstrating multifocal nerve enlargement in longitudinal views (A). Heterogeneous hypo and hyperechoic fascicular enlargement seen of the same nerve in cross section (B) with CSA measuring 68 mm². Cross sectional view of enlarged median nerve in the forearm with uniform fascicular enlargement seen in Charcot Marie Tooth Type IA (C) with CSA measuring 62 mm ${ }^{2}$. 
reflexes. The presentation of CIDP is variable and includes atypical forms such as pure motor or pure sensory CIDP, multifocal acquired demyelinating sensory motor neuropathy (MADSAM) and distal acquired demyelinating sensory (DADS) neuropathy. Abnormal nerve morphology is identified on ultrasound in $64-87 \%$ of patients. ${ }^{107-109}$ Typical sonographic findings are increased nerve CSA in a multifocal pattern, affecting proximal and distal segments and nonentrapment sites $^{110}$ (Figure 6). Like clinical features, ultrasound findings are similarly variable, with some patients even demonstrating normal nerve size on ultrasound. ${ }^{107}$

MADSAM is an asymmetric CIDP variant with a more asymmetrical, multifocal pattern of nerve enlargement on ultrasound. ${ }^{111,112}$ Enlarged hypoechoic fascicles are typically seen in segments with past or present conduction block $^{112,113}$ and seem to reduce in response to treatment. ${ }^{114}$

Several distinct ultrasound patterns in CIDP have been identified which correlate with disease duration. Three ultrasound classes were described by Padua et al ${ }^{108}$ based on CSA and echogenicity. Large hypoechoic nerves (class 1) were associated with the shortest disease duration ( $0-4$ years) when compared to normal size nerve with hyperechoic changes (class 3) (7-11 years duration). Large nerves with heterogeneous hypo- and hyperechoic fascicles (class 2 ) were also heterogenous regards disease duration (0.5-16 years).

Ultrasound can increase diagnostic accuracy in CIDP, especially when proximal segments and the brachial plexus are imaged. ${ }^{115}$ This is important because misdiagnosis is common in CIDP, especially in the atypical variants. ${ }^{116}$ One prospective study assessed 100 suspected chronic immune mediated polyneuropathy referrals with EDX and ultrasound. ${ }^{115}$ Enlargement in the proximal median nerve or C5 root (referred to as the "Short Ultrasound Protocol") was diagnostic with a sensitivity of 84.6-96.4\% and specificity of $44.9-72.8 \%$ depending on the reference standard. Importantly, 25\% (11/44) of the those ultimately diagnosed as CIDP/MMN had normal EDX but abnormal ultrasound and were responsive to immunotherapy.

Ultrasound has also been researched as a tool to differentiate between hereditary demyelinating neuropathies, CIDP and other immune mediated PN (Table 2). Various schema has been proposed to quantify these differences. CMT1A is typically associated with the largest nerves, which are homogeneously/diffusely enlarged. ${ }^{107,117}$ The pattern of enlargement is more variable and to a lesser degree in CIDP. Normal nerve calibre, focal and diffuse enlargement resembling CMT have all been described in CIDP. $^{23,107,109,118}$ Mild, regional, asymmetrical or heterogenous enlargement all point towards atypical CIDP, MMN, or GBS. ${ }^{23,107}$ Various imaging protocols and scoring systems have been proposed eg, the homogeneity score and the regional nerve enlargement index. ${ }^{119}$ The more focal pattern of nerve enlargement seen in inflammatory neuropathies can also be quantified using the intranerve variability (maximum CSA/minimum CSA for a given nerve) and the internerve variability (maximum intranerve variability/minimum intranerve variability for a given patient). ${ }^{120}$ However, these patterns and scores are predominantly based on relatively small retrospective cohorts, and larger prospective studies are required to define the optimal ultrasound protocols to differentiate these disorders. ${ }^{119}$

Ultrasound provides surrogate markers for disease severity in CIDP, such as hypervascularity, number of nerves involved and cervical nerve root CSA. ${ }^{121,122}$ Larger nerve CSA has been correlated with slower conduction velocities on EDX testing in many ${ }^{123,124}$ but not all studies. ${ }^{125}$ Nerve enlargement has also been associated with clinical weakness and disability. ${ }^{124,125}$ Additionally, ultrasound provides prognostic information in CIDP, with both decreasing intra-nerve CSA variability and normal or decreasing nerve calibre predicting treatment responsiveness. $^{126}$

Furthermore, ultrasound has potential as an outcome measure in CIDP. A study of 23 consecutive patients with CIDP followed with serial ultrasound measurements over 3 -years, noted CSA increased in $51 \%$ of nerve segments, and was associated with increased functional disability and decreased motor nerve amplitudes on EDX. ${ }^{124}$

\section{Guillain-Barre Syndrome (GBS)}

GBS is an acute immune mediated generalised polyneuropathy, characterised by ascending sensory disturbance and areflexic weakness, with both demyelinating (acute inflammatory demyelinating polyneuropathy - AIDP) and axonal forms (acute motor/sensory axonal neuropathy - AMAN/ AMSAN). The nadir is typically reached by 6 weeks, and diagnosis is clinical, supported by EDX and cerebrospinal fluid studies.

Proximal nerve and nerve root enlargement has been reported on ultrasound, although the degree and frequency are less then CMT1A and CIDP. ${ }^{23,107}$ For example, mild enlargement was reported in 8/17 upper limb nerves in one cohort, ${ }^{23}$ and $5 / 6$ patients in another cohort, although this involved only $9 \%$ of the studied nerve segments. ${ }^{127}$ Importantly, nerve enlargement can be seen as early 
Table 2 Diagnostic Sonographic Findings in Peripheral Neuropathies

\begin{tabular}{|c|c|c|c|}
\hline Neuropathy & & & Characteristic Nerve Ultrasound Findings \\
\hline \multicolumn{4}{|l|}{ Hereditary } \\
\hline & CMT & IA & Enlarged diffusely, uniformly, and symmetrically \\
\hline & & IB & Enlarged proximal segments. Reduced CSA lower limbs \\
\hline & & $\mathrm{IX}$ & Enlarged proximal and lower limb segments \\
\hline & & 2 & Normal or enlarged \\
\hline & HNPP & & Focal enlargement at entrapment sites \\
\hline & ATTRv & & Enlarged proximal segments and entrapment sites \\
\hline $\begin{array}{l}\text { Sensory } \\
\text { neuronopathies }\end{array}$ & $\begin{array}{l}\text { SCA/CANVAS } \\
\text { FRDA }\end{array}$ & & $\begin{array}{l}\text { Reduced nerve calibre } \\
\text { Enlarged upper limb and normal lower limb nerves }\end{array}$ \\
\hline \multicolumn{4}{|l|}{ Acquired } \\
\hline \multirow[t]{8}{*}{ Immune mediated } & AIDP/GBS & & $\begin{array}{l}\text { Mild proximal nerve and nerve root enlargement. Vagus nerve enlargement associated with } \\
\text { autonomic dysfunction. }\end{array}$ \\
\hline & CIDP & & Multifocal enlargement of proximal and distal segments with hypervascularity. \\
\hline & MADSAM & & Asymmetrical multifocal enlargement \\
\hline & MMNCB & & Multifocal enlargement at proximal sites with/without conduction block \\
\hline & Anti MAG & & Segmentally enlarged nerve roots, plexus, and proximal nerve with high inter-nerve variability \\
\hline & POEMS & & Focal enlargement at entrapment sites \\
\hline & Vasculitic & & Multifocal enlargement at proximal sites without plexus involvement \\
\hline & Brachial neuritis & & Ipsilateral upper limb nerve enlargement, constriction, fascicular entwinement, and torsion. \\
\hline \multirow[t]{4}{*}{ Axonal } & DPN & & Mild enlargement, especially at compression sites. Hypoechoic and hypervascular. \\
\hline & Chemotherapy & & Mild enlargement at compression sites \\
\hline & Paraproteinaemic & & Normal \\
\hline & Leprosy & & Multifocal enlargement \pm hypervascularity. \\
\hline
\end{tabular}

Abbreviations: CMT, Charcot Marie Tooth disease; HNPP, Hereditary Neuropathy with liability to Pressure Palsy; ATTRv, variant transthyretin amyloidosis; GBS, Guillain Barre Disease; CIDP, Chronic Inflammatory Demyelinating Polyradiculoneuropathy; MADSAM, Multifocal acquired demyelinating sensory and motor neuropathy; MMNCB, Multifocal Motor Neuropathy with Conduction Block; Anti MAG, Anti Myelin Associated Glycoprotein; POEMS, Polyneuropathy Organomegaly Endocrinopathy Monoclonal gammopathy and Skin changes; DPN, Diabetic Polyneuropathy; SCA, Spinocerebellar Ataxia; CANVAS, Cerebellar Ataxia Neuropathy and Vestibular Areflexia Syndrome; FRDA, Friedreich's Ataxia.

as day 1-3 of symptoms, ${ }^{23,128}$ before EDX changes are apparent. $^{23}$ The presence of enlarged cervical nerve roots and vagus nerves, together with normal nerve calibre elsewhere can differentiate GBS from CIDP with a positive predictive value $>85 \%{ }^{117}$ Vagal nerve enlargement on ultrasound has also been correlated with autonomic dysfunction in AIDP. ${ }^{128,129}$

Some studies have suggested ultrasound can be used to distinguish demyelinating and axonal variants of GBS, ${ }^{130}$ while other studies have found no difference. ${ }^{131}$ Mori et al demonstrated enlarged cervical and proximal nerve segments in 6 patients with AIDP, contrasting to enlarged distal nerve segments (forearm, wrist and ankle) in 9 patients with AMAN/AMSAN. ${ }^{130}$

Miller Fisher Syndrome (MFS) is a rare GBS variant characterised by the triad of ophthalmalgia, ataxia and areflexia, and is often associated with bilateral facial weakness. Hsueh et $\mathrm{al}^{132}$ reported significantly enlarged facial but normal limb nerves in MFS.

Ultrasound has been proposed as an outcome measure for treatment in GBS. ${ }^{129,131}$ Grimm and colleagues assessed 27 patients with GBS and 31 controls with 
ultrasound at baseline and 6 months follow up. ${ }^{129}$ Cervical spinal, medial and vagus nerves were significantly larger in GBS at baseline, but returned to normal at 6 months, except for the vagus nerve which remained enlarged in those patients with significant autonomic dysfunction.

\section{Multifocal Motor Neuropathy (MMN)}

MMN is a rare upper limb predominant demyelinating polyneuropathy characterised by slowly progressive weakness and response to treatment with intravenous immunoglobulin. ${ }^{133-135}$ In practice, MMN can be difficult to distinguish from certain ALS variants. ${ }^{136}$ Sonographically mild multifocal nerve enlargement, typically in proximal sites and the brachial plexus, is seen in up to $90 \%$ MMN patients. ${ }^{137}$ Ultrasound enlargement can also occur in clinically and electrophysiologically unaffected nerve segments. ${ }^{137}$

Importantly, nerve and nerve root enlargement on ultrasound can differentiate MMN from ALS. Grimm and colleagues demonstrated that 4 enlarged nerves/nerve roots had a $87.5 \%$ sensitivity and $94.1 \%$ specificity for distinguishing MMN from ALS in their cohort. ${ }^{138}$ Others have found that ultrasound is better at distinguishing MMN from ALS then standard EDX assessments. ${ }^{139,140}$ Ultrasound can occasionally aid in the distinction of MMN from CIDP by the presence of milder, asymmetric nerve enlargement with greater side-to-side intranerve variability, although considerable overlap exists. ${ }^{141}$

Multiple studies have demonstrated a variable association between ultrasound findings and clinical weakness, disability and EDX abnormalities. ${ }^{139,141,142}$ Rattay et al demonstrated that the nerve enlargement reduced in parallel with disability after 6-12 months of treatment in MMN, although baseline nerve enlargement did not correlate with clinical or EDX markers of severity. ${ }^{143}$ Thus, nerve ultrasound can not only improve diagnosis but also disease monitoring in MMN.

\section{Anti-Myelin Associated Glycoprotein Neuropathy (MAG)}

Anti-MAG is an immune mediated demyelinating neuropathy with distally predominant symmetrical sensorimotor impairment and prolonged distal motor latencies on EDX. Despite this the ultrasound abnormalities tend to be proximal $^{144}$ and there are no reports of distal nerve enlargement. Segmental nerve enlargement has been described in cervical nerve roots, brachial plexus, and proximal nerve segments ${ }^{145}$ with considerable inter-nerve variability. ${ }^{146}$ Nerve ultrasound has been used to distinguish anti-MAG neuropathy from similar pathologies. Specifically, nerve size is greater in MAG positive than MAG-negative paraproteinaemic neuropathy. ${ }^{146}$ Some cohorts found nerve calibre in MAG to be smaller than CIDP. ${ }^{146}$

\section{Polyneuropathy, Organomegaly, Endocrinopathy, M-Protein, Skin Changes Syndrome (POEMS)}

POEMS is a rare paraneoplastic multisystem plasma cell disorder causing a mixed axonal and demyelinating polyneuropathy that can mimic CIDP. Pathogenesis is attributed to increased vascular endothelial growth factor leading to neovascularisation and peripheral nerve oedema. ${ }^{147}$ It is somewhat surprising then, that peripheral nerve ultrasound studies have demonstrated nerve enlargement at entrapment sites only. ${ }^{148}$ Indeed, the lack of diffuse/multifocal enlargement has been offered as a means of distinguishing POEMS from CIDP. ${ }^{148}$ However, the published cases describe nerve ultrasound in the subacute setting, after significant secondary axonal degeneration has occurred, and thus the ultrasound findings in early disease remain to be defined.

\section{Brachial Neuritis}

Brachial neuritis is an idiopathic monophasic inflammatory condition affecting the branches of the brachial plexus. The typical presentation is with severe pain followed by unilateral upper limb weakness. Imaging with ultrasound and other modalities, combined with surgical exploration, have led to greater pathological understanding of this condition. It is now hypothesized that a sequence of nerve enlargement, fascicular adhesion and constriction contributes to ongoing nerve injury. ${ }^{149}$ Rotational movements of the upper limb are then thought to cause the adhered nerve to tort, with fascicular entwinement and further constriction which has been associated with poor recovery. ${ }^{149}$ The most common finding on ultrasound, seen in $74 \%$ of cases, is unilateral focal nerve enlargement, often affecting the median, radial, anterior, or posterior interosseus nerves. ${ }^{150,151}$ Other findings include partial nerve constriction, fascicular entwinement or complete nerve constriction with an hourglass morphology, described in up to $50 \%$ of cases. ${ }^{152}$ Early imaging with ultrasound can potentially identify those cases with partial or complete constriction who may benefit from surgical intervention. ${ }^{149,151}$ Diaphragmatic ultrasound can be used to diagnose phrenic nerve involvement in this condition. 


\section{Vasculitic Neuropathy}

Mononeuritis multiplex is the characteristic pattern of peripheral nerve vasculitis both in isolated nerve and systemic vasculitic disorders. This is reflected on nerve ultrasound by focal, asymmetrically enlarged nerves, in proximal segments without extension to the brachial plexus. ${ }^{153-155}$ Enlargement is described in most EDX affected nerve segments, and prominently in the tibial and fibular nerves. ${ }^{154,156,157}$ Importantly, nerve enlargement is seen in almost half of all clinically and EDX unaffected nerves. ${ }^{155}$ Hypervascularity can support a diagnosis of vasculitis PN and is reported in 19\% of cases. ${ }^{155}$ The presence of an axonal neuropathy, with multifocal nerve enlargement proximal to compression sites without plexus involvement is argued to be $94 \%$ sensitive and $88 \%$ specific for vasculitis. ${ }^{155}$ Nerve enlargement might reduce with treatment, although this is based on a single case study only. ${ }^{153}$ Nerve ultrasound has also been suggested as a tool to guide nerve biopsy. Hence, ultrasound can improve diagnosis in PN vasculitis and has the potential to guide biopsy sites and support treatment monitoring.

\section{Hereditary Neuropathies}

Hereditary neuropathies are among the most studied conditions in the field of neuromuscular ultrasound. The disorders discussed below are just some of the hereditary conditions that have been studied. There are many others where no data exists.

\section{Charcot Marie Tooth (CMT)}

CMT1A is the most common form of CMT, caused by an autosomal dominant duplication of the peripheral myelin protein 22 gene, resulting in a demyelinating PN. Ultrasound in CMT1A demonstrates diffuse symmetrical nerve CSA increase in $89-100 \%$ of patients ${ }^{158-160}$ (Figure 6C). This occurs from the brachial plexus and proximal nerve segments to the small sensory nerves such as the sural and auricular nerves. ${ }^{158}$ Nerve enlargement is detectable from as young as 19 months of age, ${ }^{161}$ and as such ultrasound is an ideal noninvasive diagnostic aid in young children. Larger CSA has been associated with more severe disease, measured with the CMT neuropathy score. ${ }^{158,162}$ In addition, a number of studies have demonstrated a correlation between the degree of nerve enlargement and neurophysiological dysfunction, ${ }^{158,162}$ although this has not been a universal finding. ${ }^{159}$

CMT1B is another demyelinating form of CMT, due to Myelin Protein Zero mutations. Ultrasound in CMT1B demonstrates nerve enlargement proximally, ${ }^{163,164}$ but reduced CSA in the lower limbs, helping to distinguish it from CMT1A. ${ }^{164}$ CMT1X is an X linked mutation of the gap junction associated protein and demonstrates symmetrically enlarged CSA in proximal segments and lower limbs on ultrasound. ${ }^{165}$ Finally, CMT2 is a heterogenous collection of variably inherited axonal polyneuropathies, with similarly variable findings on ultrasound. ${ }^{100,166}$

Research into nerve ultrasound as a longitudinal biomarker in CMT has been limited to date. A small study of 15 adults with CMT1A over 5 years failed to demonstrate a change in nerve calibre when assessing the sural and median nerves. ${ }^{167}$

Although outside the scope of this review, muscle ultrasound in a cohort with CMT has demonstrated reduced thickness and increased echointensity of the first dorsal interossei and tibialis anterior muscles. ${ }^{168}$ This was more pronounced in CMT1A compared to CMTX1 and CMT2A patients, and correlate with degree of muscle weakness. Consequently, nerve and possibly muscle ultrasound can improve diagnosis and assessments of severity in CMT.

\section{Hereditary Neuropathy with Liability to Pressure Palsies (HNPP)}

HNPP is caused by an autosomal recessive deletion of the PMP22 gene, leading to multiple painless entrapment mononeuropathies. The classical ultrasound finding in HNPP is multiple areas of nerve enlargement at entrapment sites, ${ }^{169,170}$ but enlargement at non entrapment sites have also been described. ${ }^{171}$ Sonographic findings such as CSA do not correlate with neurophysiological parameters, such as the distal motor latency. ${ }^{172}$

\section{Hereditary ATTR Amyloidosis}

Variant or hereditary transthyretin amyloidosis is an autosomal dominant disorder, where point mutations in the transthyretin gene results in an axonal sensorimotor and autonomic neuropathy. The recent development of disease modifying therapy has prompted great interest in diagnostic and treatment biomarkers. Ultrasound studies in vATTR Amyloidosis have reported increased nerve CSA at entrapment sites, proximal nerve segments and the brachial plexus when compared to healthy controls. ${ }^{100,173}$ CSA is also greater in symptomatic vATTR then asymptomatic carriers ${ }^{100}$ and in those with abnormal motor conduction studies. ${ }^{174}$ While carpal tunnel syndrome is common in VATTR, the median nerve CSA at the wrist is smaller than in idiopathic CTS and is discordant with 
EDX severity. ${ }^{175}$ This has been suggested as an early clinical clue for vATTR in patients presenting with CTS.

\section{Cerebellar Ataxia, Neuropathy and Vestibular} Areflexia Syndrome (CANVAS)

CANVAS is an adult-onset disorder caused by mutation in the RFC1 gene. A sensory neuronopathy is universally seen in patients with CANVAS, ${ }^{176}$ and can be detected on ultrasound as a reduction in CSA of the median, ulnar, tibial, and sural nerves. ${ }^{177} \mathrm{~A}$ reduced median and ulnar nerve CSA $<5 \mathrm{~mm}^{2}$ in the mid-forearm or mid-humerus demonstrate a sensitivity of 79-93\%, specificity $100 \%$ and area under the curve (AUC) of $0.97-0.99^{178}$ for distinguishing CANVAS from healthy controls.

\section{Spinocerebellar Ataxia (SCA) 2}

SCA 2 is an autosomal dominant CAG triplet repeat mutation in the Ataxin 2 gene, resulting in cerebellar ataxia, sensory motor neuropathy, pyramidal and extrapyramidal dysfunction. ${ }^{179}$ Reduced nerve CSA on ultrasound is seen in the majority $(74 \%)$ of patients and correlates with the presence of a sensory neuronopathy. ${ }^{177}$

\section{Friedrich Ataxia}

Friedrich Ataxia is an autosomal dominant GAA triplet repeat disorder affecting the Frataxin gene, leading to cerebellar ataxia, cardiomyopathy and sensory neuropathy/neuronopathy. Interestingly, upper limb nerve CSA is enlarged in Friedrich ataxia, attributed to dysmyelintation and perineurial connective tissue proliferation, ${ }^{180}$ while lower limb nerve CSA is normal.

\section{Axonal Neuropathies}

The utility of ultrasound in axonal PN is less well characterised. It was hypothesized initially that nerve calibre would be reduced in axonal neuropathies. However, ultrasound has revealed that nerves are typically either normal or slightly enlarged. ${ }^{23,119}$ The potential application of nerve ultrasound to many forms of axonal neuropathy, eg, toxic, metabolic, inflammatory aetiology remains to be defined by future research.

\section{Diabetic Polyneuropathy (DPN)}

DPN is characterised sonographically by mild hypoechoic nerve enlargement, notably at compression sites. Several studies have reported enlarged CSA for the median and tibial nerves of Type 1 and Type 2 Diabetics with PN when compared to healthy controls. ${ }^{181-184}$ Nerve enlargement can also predate clinical neuropathy, ${ }^{185}$ and increases further once DPN develops. ${ }^{186}$ In addition, the degree of enlargement and vascularity are biomarkers of severity, and correlate with clinical and EDX parameters. ${ }^{182,184,185}$ Further, in type 2 diabetics nerve ultrasound can demonstrate enlarged fascicles and marked hypoechogenicity when compared to controls, and this to correlates with EDX abnormalities. ${ }^{184,185}$ Type 2 diabetics with metabolic syndrome also demonstrate larger nerves and more severe neuropathy then diabetics without metabolic syndrome. ${ }^{187}$ Furthermore, increased tibial nerve stiffness on shear wave elastography is $90 \%$ sensitive and $85 \%$ specific for diabetes and increases with the development of DPN. ${ }^{188}$

\section{Chemotherapy-Associated Neuropathy}

Chemotherapy-associated PN demonstrates mild, often asymptomatic nerve enlargement at compression sites in $69 \%$ of patients and may point to nerve vulnerability to mechanical stress. ${ }^{188}$ In contrast, Lycan et al studied 20 patients with breast cancer exposed to taxane-based chemotherapy and reported reduced sural nerve calibre on ultrasound. ${ }^{190}$ Nerve size was further correlated with older age, longer time since exposure and intraepidermal nerve fibre density on skin biopsy.

\section{Leprosy}

Leprosy secondary to infection with Mycobacterium leprae is a prevalent cause for PN outside the western world $^{191}$ and has been well studied with peripheral nerve ultrasound. Leprosy is characterised by both axonal and segmentally demyelinating $\mathrm{PN}$ with palpably thickened nerves and skin changes. Leprosy typically manifests with recurrent immune reactions referred to as "active leprosy". Ultrasound studies have reported multiple asymmetric nerve enlargement with epineurial thickening. ${ }^{32,192-}$

195 "Active leprosy" is associated with nerve hypervascularisation in $55-71 \%$ of patients and decreases to $2.7-5.9 \%$ with treatment. ${ }^{193,195}$ Thus, peripheral nerve ultrasound has potential as both a diagnostic and monitoring tool in Leprosy. ${ }^{193}$

\section{Paediatric Nerve Ultrasound}

EDX in children is challenging. EDX testing is potentially painful, with pain more frequently experienced when EMG is performed, when greater than one muscle and proximal muscles are tested. ${ }^{196}$ It is unsurprising therefore that younger age, especially under 3 years, is associated with inadequate and incomplete EDX in paediatric cohorts. ${ }^{196}$ Furthermore, EMG relies on active muscle 
recruitment and patient participation which is limited in the very young. ${ }^{197}$ Nerve imaging with MRI in children is also challenging due to the need to lie still for prolonged periods which may necessitate sedation. Nerve ultrasound on the other hand is painless, quick, adaptable, cost effective and well tolerated in paediatric patients. ${ }^{198}$ It seems natural therefore to see a recent growth in paediatric neuromuscular ultrasound research. ${ }^{107,199}$

Peripheral nerves increase in size as we age, meaning children with enlarged nerves may be incorrectly interpreted as normal if adult references values are applied. Therefore, the accurate interpretation of abnormal nerve CSA is reliant on the ongoing expansion age-specific normative ultrasound data. ${ }^{200,201}$ Zaidman et $\mathrm{al}^{23}$ examined 40 healthy children aged 2-17, among a larger cohort of 90 adults and children, and reported a range of normal CSA values. Of interest, an association between height and nerve CSA was seen, and was stronger in children $(\mathrm{r}=0.9$, $\mathrm{P}<0.001)$ than adults $(\mathrm{r}=0.5, \mathrm{P}<0.001)$. Cartwright et $\mathrm{al}^{202}$ recorded peripheral nerve CSA in a further 43 children aged 3 months to 16 years as well 160 adults. Age was the strongest predictor of nerve CSA, although height and BMI were also predictive. Druzhinin et $\mathrm{al}^{201}$ systematically collected ultrasound CSA measurements in an children and young adults, scanning 72 healthy subjects aged 2-30 years. Their data suggest that nerve CSA is independently associated with age and weight but not height, differing from previous studies by Zaidman ${ }^{23}$ and Cartwright. ${ }^{201}$ Zaidman and Cartwright analysed for associations using pooled CSA values from all nerve measurements while Druzhinin analysed each nerve measurement individually, and this may explain their different findings. All three studies found nerve size plateaued at 12-14 years leading the authors to conclude that paediatric specific normative values are essential to interpret imaging in subjects below this cut off. The intra and inter-nerve variability was measured in Zaidman and Druzhinin's populations and interestingly did not differ significantly with age. ${ }^{23,201}$ This may be a potential age-independent measure to use where normative data is limited.

Entrapment mononeuropathies are uncommon in children, and when they do occur ultrasound can detect unusual causes such as mucopolysaccharidosis. ${ }^{203,204}$ Research in adult populations has been used to argue for supplementation or even replacement of standard EDX assessments with neuromuscular ultrasound in certain focal mononeuropathies such as carpal tunnel syndrome. ${ }^{46,205,206}$ A similar argument could be made for children with mononeuropathies but will require further studies to evaluate.

Polyneuropathies on the other hand are common in children and sonographic nerve changes are detectable in certain hereditary neuropathies such as CMT from a very young age. ${ }^{107,161}$ Further, nerve CSA in children with CMT1A correlates with disease severity, as well as age, height and weight. ${ }^{161}$ Furthermore, ultrasound can aid in the distinction between hereditary and acquired inflammatory polyneuropathies in this age group. ${ }^{107,119}$ Zaidman et al performed nerve ultrasound in 128 adults and children with a range of hereditary and acquired peripheral neuropathies. Thirty-five CMT1 patients age 2-71 years were examined and 8 out of 9 children with CMT demonstrated diffuse sonographic nerve enlargement.

Ultrasound has also been used to assess neonatal brachial plexopathy, which occurs in up to 3 in 1000 live births. ${ }^{207}$ The current standard is a 3-month period of observation for spontaneous recovery followed by surgical exploration where recovery is poor. ${ }^{208}$ In 2015 , Somashekar et all compared preoperative US to surgical exploration in the detection of traction neuromas in 33 children. ${ }^{209}$ Of their cohort, 31 of the 33 surgically identified neuromas were detectable on US. Furthermore, muscle atrophy was identified in 11 children and guided spinal accessory and supra scapular nerve transfers in 8 of those patients.

Another advantage of ultrasound is its potential to limit the amount of EDX testing required to achieve a diagnosis. Rardin et al ${ }^{210}$ compared retrospective data from 21 children who were assessed by ultrasound prior to EDX with 84 aged-matched control subjects who had EDX assessment alone. Those subjects investigated with ultrasound first required less EDX tests, with fewer nerve stimulations and fewer muscles sampled by EMG. This led the authors to conclude an ultrasound first approach should be considered in paediatric patients to limit EDX testing.

Therefore, ultrasound has a number of distinct advantages in paediatric neuromuscular assessment and its role is likely to grow in this population. Further studies are needed to better define normal nerve size, as well as more detailed structural assessment such as fascicle measurements, echotexture and elastography.

\section{Motor Neuron Diseases}

Disorders of the motor neuron include Amyotrophic Lateral Sclerosis (ALS), Spinal Muscular Atrophy (SMA) and Spinal Bulbar Muscular Atrophy (SBMA or Kennedy's disease) and Poliomyelitis. Diagnostic delay is 
a significant issue in these disorders, for instance in ALS the median time to diagnosis is 11.5 months after onset of symptoms. ${ }^{210}$ In SMA, the emergence of disease modifying therapy has generated the need for accessible, accurate, responsive, and reliable outcome measures. Hence, ultrasound has clear potential to improve the diagnosis and monitoring of motor neuron disease, and there is a growing body of literature supporting its use in ALS and SMA.

\section{Amyotrophic Lateral Sclerosis}

ALS is a fatal neurodegenerative disorder affecting the motor neuron, with a median survival of 3-5 years, ${ }^{212-}$ 214 characterised by dysfunction of both upper and lower motor neurons (UMN and LMN) as well as cognition. ${ }^{213}$ Clinical heterogeneity exists, and there is an absence of pathognomonic investigations, leading to significant diagnostic delay. ${ }^{215}$ To better define the investigations of ALS and to promote recruitment of patients to clinical trials, the
El Escorial and revised El Escorial (rEEC) were developed incorporating the presence of upper (UMN) and lower motor neuron (LMN) signs. ${ }^{216-218}$ It was argued that the rEEC, although specific, was lacking in sensitivity, particularly in the early stages of disease, and consequently the Awaji criteria and more recently the Gold Coast criteria were developed. ${ }^{220-224}$ These included the identification of fasciculations on EMG as an LMN sign and have contributed to the increased sensitivity in diagnosing ALS. ${ }^{216,224-}$ 226 Neuromuscular ultrasound offers greater sensitivity then EMG in the detection of fasciculations especially in bulbar structures and thus has the potential to further improve the diagnostic sensitivity of the criteria. ${ }^{228}$ Further, muscle ultrasound in ALS can improve diagnosis through the detection of reduced muscle thickness and increased muscle echointensity ${ }^{98,227-229}$ (Figure 7). Furthermore, quantitative measures of muscle echotexture have been used as diagnostic biomarkers and responsive outcome measures in ALS. ${ }^{230,231}$

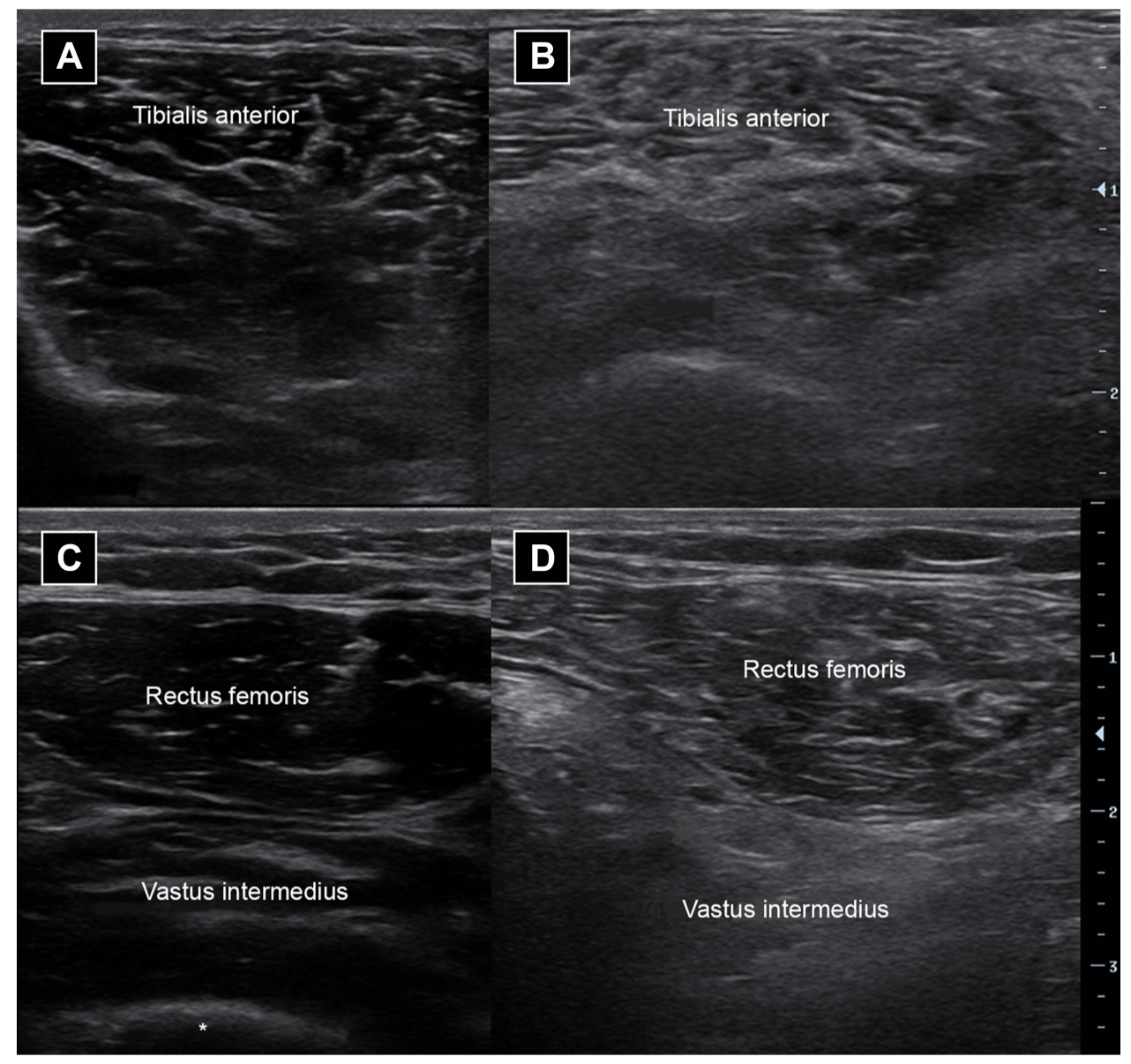

Figure 7 Cross-sectional image of a normal tibialis anterior muscle (A) and quadriceps muscles (C) in a healthy individual. Cross-sectional image of abnormal tibialis anterior muscle (B) and vastus intermedius muscle and to a lesser extent rectus femoris muscle (D) in a person with amyotrophic lateral sclerosis. Note in the abnormal muscles there is atrophy with increased brightness or echointensity with a loss of the underlying bone reflection $(*)$. 
A reduction in motor nerve and cervical nerve root calibre with a sparing of sensory nerves has been consistently described in $\mathrm{ALS}^{232-235}$ and is likely to reflect motor axon loss. This occurs in both clinically affected and unaffected regions. ${ }^{233}$ Nerve ultrasound can distinguish ALS from mimic disorders such as MMN and peripheral nerve hyperexcitability syndromes. ${ }^{236}$ Specifically an increased distal:proximal CSA ratio of the median nerve can distinguish ALS and reflects the relative density of motor fibres in the proximal portion of the nerve. ${ }^{236}$ Additionally, nerve ultrasound is abnormal in preclinical ALS where axonal degeneration is compensated and thus muscle wasting/weakness not yet apparent. ${ }^{233,237}$ Detecting the submillimetre nerve CSA changes in this preclinical state will likely improve as higher frequency ultrasound probes are developed and in wider use. ${ }^{237,238}$ One current limitation of nerve ultrasound is its insensitivity as a tool to monitor disease progression. ${ }^{238}$ Furthermore, nerve ultrasound measurements are not consistently correlated with disease severity on clinical and EDX measures, in part due to the confounding effect of UMN dysfunction. ${ }^{235}$

Bulbar motor neuron dysfunction, associated with dysphagia, is common in ALS, and can be measured by ultrasound in several ways. Video ultrasonography, a technique to dynamically assess tongue position and morphotexture during attempted swallow, is an early and sensitive measure of dysphagia in ALS. ${ }^{239}$ Further, ultrasound measures of tongue thickness are reduced in ALS, and this is most marked in those patients with bulbar onset disease and lower BMI. ${ }^{240}$ Furthermore, tongue thickness decreases with disease progression and may be used to monitor dysphagia and potentially guide timing of nutritional interventions such as parenteral feeding which are associated with improved survival in ALS. ${ }^{241,242}$ Lastly, minimal change in tongue thickness during swallowing, measured as a reduced "thickness ratio" is a specific marker of UMN bulbar dysfunction. ${ }^{243}$ Thus, dynamic tongue ultrasound has potential as a diagnostic and prognostic biomarker of bulbar dysfunction in ALS.

Respiratory dysfunction is universal in ALS as the disease progresses. ${ }^{244}$ Monitoring respiratory dysfunction, traditionally with spirometry, is essential to guide institution of non-invasive ventilation which can improve survival and quality of life. ${ }^{244-246}$ A major limitation of spirometry in ALS is its poor reliability in the setting of bulbar and facial weakness as well as cognitive impairment. Dynamic diaphragmatic ultrasound thickness, measured as inspiration:expiration thickness or "thickening ratio", offers an alternative measure in such patients. Ultrasound diaphragm thickness and thickening ratio are reliable in ALS, ${ }^{247}$ and correlate with vital capacity, hypercapnia, hypoventilation and motor disability more broadly. ${ }^{247}$ Thus, diaphragmatic ultrasound represents an important diagnostic biomarker for respiratory dysfunction in ALS, ${ }^{248}$ although at this stage it remains experimental and is not a substitute for standard measurements.

\section{Spinal Muscular Atrophy (SMA)}

SMA is an autosomal recessive disorder of spinal lower motor neurons, caused by the mutation in the survival motor neuron (SMN1) gene. This ranges in severity from the severe type 1 SMA with onset before 6 months of age to Type 4 SMA with adult onset. There is considerable interest in biomarkers for diagnosis and disease progression in SMA due to the emergence of disease modifying therapy in the form of antisense oligonucleotides (Nusinersen and Risdiplan) and the gene replacement therapy (onasemnogene abeparvovec-xioi). Nerve ultrasound can distinguish adult onset SMA from mimicking disorders such as CIDP and MMNCB, based on reduced proximal nerve and nerve root CSA in SMA. ${ }^{249}$

In addition, high-frequency nerve ultrasound may provide prognostic information. This was suggested in a pilot study of 3 SMA patients using ultra high-frequency median nerve imaging. ${ }^{250} \mathrm{~A}$ reduced median nerve CSA and fascicle number was seen in the most severely affected subject (SMA I) relative to controls. Further, quantitative muscle ultrasound echo intensity, expressed as a "Luminosity ratio", was increased in a cohort of SMA II and III subjects compared to healthy controls. ${ }^{251}$ Luminosity ratio was higher in more severe disease (SMA II) and correlated with dynamometry measures of strength. This suggests the diagnostic and monitoring potential for muscle ultrasound in SMA. Further research is needed to assess the role of nerve and muscle ultrasound in SMA.

\section{Conclusion}

The use of ultrasound to assess peripheral nerves in routine clinical practice is increasing due to its safety, accessibility, and dynamic quality. Current ultrasound technology provides excellent resolution of peripheral nerves and the flexibility of point of care machines allow easy integration into neuromuscular and electrodiagnostic clinics. Ultrasound adds critical structural information to compliment clinical and EDX assessments, contributing to improved diagnosis and 
pathophysiological understanding of peripheral nerve disorders. While nerve ultrasound is most frequently used to diagnose focal compressive mononeuropathy, its application has grown to include traumatic nerve injury, generalised peripheral neuropathy, motor neuron diseases and a range of other neuromuscular conditions in both adult and paediatric populations. Despite the operator-dependant nature of ultrasound, further development of quantitative measures, standardised protocols and consensus scoring frameworks will allow wider application and lead to improved diagnosis of peripheral nerve disease.

\section{Acknowledgments}

Funding support from the National Health and Medical Research Council of Australia is gratefully acknowledged.

\section{Disclosure}

Professor Matthew C Kiernan reports grants from NHMRC, is the Editor-in-Chief of Journal of Neurology, Neurosurgery \& Psychiatry, during the conduct of the study. The authors report no conflicts of interest in this work. There are no financial interests or other conflicts of interest to declare.

\section{References}

1. Latinovic R, Gulliford MC, Hughes RA. Incidence of common compressive neuropathies in primary care. $J$ Neurol Neurosurg Psychiatry. 2006;77(2):263-265. doi:10.1136/jnnp.2005.066696

2. Hulkkonen S, Lampainen K, Auvinen J, Miettunen J, Karppinen J, Ryhänen J. Incidence and operations of median, ulnar and radial entrapment neuropathies in Finland: a nationwide register study. $J$ Hand Surg Eur Vol. 2020;45(3):226-230. doi:10.1177/ 1753193419886741

3. Musolin K, Ramsey JG, Wassell JT, Hard DL. Prevalence of carpal tunnel syndrome among employees at a poultry processing plant. Appl Ergon. 2014;45(6):1377-1383. doi:10.1016/j.apergo.2014.03.005

4. Musolin KM, Ramsey JG. Carpal tunnel syndrome prevalence: an evaluation of workers at a raw poultry processing plant. Int J Occup Environ Health. 2017;23(4):282-290. doi:10.1080/ 10773525.2018.1474420

5. Gonzalez NL, Hobson-Webb LD. Neuromuscular ultrasound in clinical practice: a review. Clin Neurophysiol Pract. 2019;4:148-163. doi:10.1016/j.cnp.2019.04.006

6. Jablecki CK, Andary MT, Floeter MK, et al. Practice parameter: electrodiagnostic studies in carpal tunnel syndrome. Report of the American Association of Electrodiagnostic Medicine, American Academy of Neurology, and the American Academy of Physical Medicine and Rehabilitation. Neurology. 2002;58(11):1589-1592. doi:10.1212/wnl.58.11.1589

7. Boonyapisit K, Katirji B, Shapiro BE, Preston DC. Lumbrical and interossei recording in severe carpal tunnel syndrome. Muscle Nerve. 2002;25(1):102-105. doi:10.1002/mus. 10002

8. MacDonald BK, Cockerell OC, Sander JW, Shorvon SD. The incidence and lifetime prevalence of neurological disorders in a prospective community-based study in the UK. Brain. 2000;123(Pt 4):665-676. doi:10.1093/brain/123.4.665
9. Simmons Z, Feldman EL. Update on diabetic neuropathy. Curr Opin Neurol. 2002;15(5):595-603. doi:10.1097/00019052200210000-00010

10. Kandula T, Farrar MA, Cohn RJ, et al. Chemotherapy-induced peripheral neuropathy in long-term survivors of childhood cancer: clinical, neurophysiological, functional, and patient-reported outcomes. JAMA Neurol. 2018;75(8):980-988. doi:10.1001/ jamaneurol.2018.0963

11. Ellis RJ, Rosario D, Clifford DB, et al. Continued high prevalence and adverse clinical impact of human immunodeficiency virus-associated sensory neuropathy in the era of combination antiretroviral therapy: the CHARTER Study. Arch Neurol. 2010;67(5):552-558. doi:10.1001/archneurol.2010.76

12. Timmins HC, Li T, Huynh W, et al. Electrophysiological and phenotypic profiles of taxane-induced neuropathy. Clin Neurophysiol. 2020;131(8):1979-1985. doi:10.1016/j. clinph.2020.02.028

13. Park SB, Goldstein D, Krishnan AV, et al. Chemotherapy-induced peripheral neurotoxicity: a critical analysis. CA Cancer J Clin. 2013;63(6):419-437. doi:10.3322/caac.21204

14. Li T, Timmins HC, King T, Kiernan MC, Goldstein D, Park SB. Characteristics and risk factors of bortezomib induced peripheral neuropathy: a systematic review of Phase III trials. Hematol Oncol. 2020;38(3):229-243. doi:10.1002/hon.2706

15. Simon NG, Talbott J, Chin CT, Kliot M. Peripheral nerve imaging. Handb Clin Neurol. 2016;136:811-826. doi:10.1016/ b978-0-444-53486-6.00040-5

16. Latov N. Diagnosis and treatment of chronic acquired demyelinating polyneuropathies. Review. Nat Rev Neurol. 2014;10 (8):435-446. doi:10.1038/nrneurol.2014.117

17. Neligan A, Reilly MM, Lunn MP. CIDP: mimics and chameleons. Pract Neurol. 2014;14(6):399-408. doi:10.1136/practneurol2014-000831

18. Latov N. Biomarkers of CIDP in patients with diabetes or CMT1. J Peripher Nerv Syst. 2011;16 Suppl 1:14. doi:10.1111/j.15298027.2011.00299.x

19. Fornage BD. Peripheral nerves of the extremities: imaging with US. Radiology. 1988;167(1):179-182. doi:10.1148/ radiology.167.1.3279453

20. Simon NG, Cage T, Narvid J, Noss R, Chin C, Kliot M. Highresolution ultrasonography and diffusion tensor tractography map normal nerve fascicles in relation to schwannoma tissue prior to resection. J Neurosurg. 2014;120(5):1113-1117. doi:10.3171/ 2014.2.Jns 131975

21. Simon NG, Ralph JW, Poncelet AN, Engstrom JW, Chin C, Kliot M. A comparison of ultrasonographic and electrophysiologic 'inching' in ulnar neuropathy at the elbow. Clin Neurophysiol. 2015;126(2):391-398. doi:10.1016/j.clinph.2014.05.023

22. Tagliafico A, Cadoni A, Fisci E, Bignotti B, Padua L, Martinoli C. Reliability of side-to-side ultrasound cross-sectional area measurements of lower extremity nerves in healthy subjects. Muscle Nerve. 2012;46(5):717-722. doi:10.1002/mus.23417

23. Zaidman CM, Al-Lozi M, Pestronk A. Peripheral nerve size in normals and patients with polyneuropathy: an ultrasound study. Muscle Nerve. 2009;40(6):960-966. doi:10.1002/mus.21431

24. Cartwright MS, Passmore LV, Yoon JS, Brown ME, Caress JB, Walker FO. Cross-sectional area reference values for nerve ultrasonography. Muscle Nerve. 2008;37(5):566-571. doi:10.1002/mus.21009

25. Haun DW, Cho JC, Kettner NW. Normative cross-sectional area of the C5-C8 nerve roots using ultrasonography. Ultrasound Med Biol. 2010;36(9):1422-1430. doi:10.1016/j.ultrasmedbio.2010.05.012

26. Won SJ, Kim BJ, Park KS, Kim SH, Yoon JS. Measurement of cross-sectional area of cervical roots and brachial plexus trunks. Muscle Nerve. 2012;46(5):711-716. doi:10.1002/mus.23503 
27. Tagliafico A, Altafini L, Garello I, Marchetti A, Gennaro S, Martinoli C. Traumatic neuropathies: spectrum of imaging findings and postoperative assessment. Semin Musculoskelet Radiol. 2010;14(5):512-522. doi:10.1055/s-0030-1268071

28. Boom J, Visser LH. Quantitative assessment of nerve echogenicity: comparison of methods for evaluating nerve echogenicity in ulnar neuropathy at the elbow. Clin Neurophysiol. 2012;123 (7):1446-1453. doi:10.1016/j.clinph.2011.10.050

29. Brill NA, Tyler DJ. Quantification of human upper extremity nerves and fascicular anatomy. Muscle Nerve. 2017;56 (3):463-471. doi:10.1002/mus.25534

30. Puma A, Azulay N, Grecu N, et al. Comparison of high-frequency and ultrahigh-frequency probes in chronic inflammatory demyelinating polyneuropathy. $J$ Neurol. 2019;266(9):2277-2285. doi:10.1007/s00415-019-09392-z

31. Martinoli C, Bianchi S, Gandolfo N, Valle M, Simonetti S, Derchi LE. US of nerve entrapments in osteofibrous tunnels of the upper and lower limbs. Radiographics. 2000;20:S213. doi:10.1148/radiographics.20.suppl_1.g00oc08s199

32. Jain S, Visser LH, Praveen TL, et al. High-resolution sonography: a new technique to detect nerve damage in leprosy. PLoS Negl Trop Dis. 2009;3(8):e498. doi:10.1371/journal.pntd.0000498

33. Borire AA, Arnold R, Pussell BA, et al. Haemodialysis alters peripheral nerve morphology in end-stage kidney disease. Clin Neurophysiol. 2017;128(1):281-286. doi:10.1016/j. clinph.2016.09.010

34. Wee TC, Simon NG. Ultrasound elastography for the evaluation of peripheral nerves: a systematic review. Muscle Nerve. 2019;60 (5):501-512. doi:10.1002/mus.26624

35. Zakrzewski J, Zakrzewska K, Pluta K, Nowak O, MiłoszewskaPaluch A. Ultrasound elastography in the evaluation of peripheral neuropathies: a systematic review of the literature. Pol J Radiol. 2019;84:e581-e591. doi:10.5114/pjr.2019.91439

36. Gallardo E, Noto Y, Simon NG. Ultrasound in the diagnosis of peripheral neuropathy: structure meets function in the neuromuscular clinic. J Neurol Neurosurg Psychiatry. 2015;86 (10):1066-1074. doi:10.1136/jnnp-2014-309599

37. Mallouhi A, Pülzl P, Trieb T, Piza H, Bodner G. Predictors of carpal tunnel syndrome: accuracy of gray-scale and color Doppler sonography. AJR Am J Roentgenol. 2006;186(5):1240-1245. doi:10.2214/ajr.04.1715

38. Akcar N, Ozkan S, Mehmetoglu O, Calisir C, Adapinar B. Value of power Doppler and gray-scale US in the diagnosis of carpal tunnel syndrome: contribution of cross-sectional area just before the tunnel inlet as compared with the cross-sectional area at the tunnel. Korean J Radiol. 2010;11(6):632-639. doi:10.3348/ kjr.2010.11.6.632

39. Aseem F, Williams JW, Walker FO, Cartwright MS Neuromuscular ultrasound in patients with carpal tunnel syndrome and normal nerve conduction studies. Muscle Nerve. 2017;55(6):913-915. doi:10.1002/mus.25462

40. Padua L, Liotta G, Di Pasquale A, et al. Contribution of ultrasound in the assessment of nerve diseases. Eur J Neurol. 2012;19 (1):47-54. doi:10.1111/j.1468-1331.2011.03421.x

41. Miller TT, Reinus WR. Nerve entrapment syndromes of the elbow, forearm, and wrist. AJR Am J Roentgenol. 2010;195 (3):585-594. doi:10.2214/ajr.10.4817

42. Jacobson JA, Fessell DP, Lobo Lda G, Yang LJ. Entrapment neuropathies I: upper limb (carpal tunnel excluded). Semin Musculoskelet Radiol. 2010;14(5):473-486. doi:10.1055/s-00301268068

43. Csillik A, Bereczki D, Bora L, Arányi Z. The significance of ultrasonographic carpal tunnel outlet measurements in the diagnosis of carpal tunnel syndrome. Clin Neurophysiol. 2016;127 (12):3516-3523. doi:10.1016/j.clinph.2016.09.015
44. Paliwal PR, Therimadasamy AK, Chan YC, Wilder-Smith EP Does measuring the median nerve at the carpal tunnel outlet improve ultrasound CTS diagnosis? J Neurol Sci. 2014;339(12):47-51. doi:10.1016/j.jns.2014.01.018

45. Padua L, Pazzaglia C, Insola A, et al. Schwannoma of the median nerve (even outside the wrist) may mimic carpal tunnel syndrome. Neurol Sci. 2006;26(6):430-434. doi:10.1007/s10072-006-0527-9

46. Cartwright MS, Hobson-Webb LD, Boon AJ, et al. Evidencebased guideline: neuromuscular ultrasound for the diagnosis of carpal tunnel syndrome. Muscle Nerve. 2012;46(2):287-293. doi:10.1002/mus.23389

47. Bayrak IK, Bayrak AO, Kale M, Turker H, Diren B. Bifid median nerve in patients with carpal tunnel syndrome. J Ultrasound Med. 2008;27(8):1129-1136. doi:10.7863/jum.2008.27.8.1129

48. Tan TC, Yeo CJ, Smith EW. High definition ultrasound as diagnostic adjunct for incomplete carpal tunnel release. Hand Surg. 2011;16(3):289-294. doi:10.1142/s0218810411005564

49. Doğan Y, Kara M, Aydin G, Gök M, Ozçakar L. Ultrasonographic imaging of the median nerve with a struthers ligament. Am J Phys Med Rehabil. 2018;97(11):e111-e112. doi:10.1097/ phm.0000000000000930

50. Créteur V, Madani A, Sattari A, Bianchi S. Sonography of the pronator teres: normal and pathologic appearances. $J$ Ultrasound Med. 2017;36(12):2585-2597. doi:10.1002/jum.14306

51. Guclu D, Arican M, Unlu EN. Median nerve entrapment due to accessory palmaris longus muscle: MRI and sonography findings. BMJ Case Rep. 2018;bcr-2018-224852. doi:10.1136/bcr-2018224852

52. Liu J, Zhong K, Lin D. Median nerve compression caused by superficial brachial artery: an unusual clinical case. J Int Med Res. 2020;48(12):300060520969043. doi:10.1177/0300060520969043

53. Stefanou MI, Schubert V, Ruschil C, et al. Median nerve dissection after brachial artery catheterization revealed by high-resolution ultrasound. Clin Neurophysiol. 2019;130 (7):1081-1082. doi:10.1016/j.clinph.2019.04.007

54. Omejec G, Podnar S. Precise localization of ulnar neuropathy at the elbow. Clin Neurophysiol. 2015;126(12):2390-2396. doi:10.1016/j.clinph.2015.01.023

55. Beekman R, Visser LH, Verhagen WI. Ultrasonography in ulnar neuropathy at the elbow: a critical review. Muscle Nerve. 2011;43 (5):627-635. doi:10.1002/mus.22019

56. Cheng Y, Xu X, Chen W, Wang Y. Doppler sonography for ulnar neuropathy at the elbow. Muscle Nerve. 2016;54(2):258-263. doi:10.1002/mus. 25022

57. Frijlink DW, Brekelmans GJ, Visser LH. Increased nerve vascularization detected by color Doppler sonography in patients with ulnar neuropathy at the elbow indicates axonal damage. Muscle Nerve. 2013;47(2):188-193. doi:10.1002/mus.23505

58. Beekman R, Van Der Plas JP, Uitdehaag BM, Schellens RL, Visser LH. Clinical, electrodiagnostic, and sonographic studies in ulnar neuropathy at the elbow. Muscle Nerve. 2004;30 (2):202-208. doi:10.1002/mus.20093

59. Simon NG. Treatment of ulnar neuropathy at the elbow - An ongoing conundrum. Clin Neurophysiol. 2018;129 (8):1716-1717. doi:10.1016/j.clinph.2018.06.006

60. de Ruiter GCW, de Jonge JGH, Vlak MHM, van Loon-felter AE. Ulnar neuropathy caused by muscular arcade of struthers. World Neurosurg. 2020;142:128-130. doi:10.1016/j.wneu.2020.06.179

61. Ozturk E, Sonmez G, Colak A, et al. Sonographic appearances of the normal ulnar nerve in the cubital tunnel. J Clin Ultrasound. 2008;36(6):325-329. doi:10.1002/jcu.20486

62. Van Den Berg PJ, Pompe SM, Beekman R, Visser LH. Sonographic incidence of ulnar nerve (sub)luxation and its associated clinical and electrodiagnostic characteristics. Muscle Nerve. 2013;47(6):849-855. doi:10.1002/mus.23715 
63. Okamoto M, Abe M, Shirai H, Ueda N. Morphology and dynamics of the ulnar nerve in the cubital tunnel. Observation by ultrasonography. $J$ Hand Surg Br. 2000;25(1):85-89. doi:10.1054/jhsb.1999.0317

64. Omejec G, Podnar S. Does ulnar nerve dislocation at the elbow cause neuropathy? Muscle Nerve. 2016;53(2):255-259. doi:10.1002/mus.24786

65. Omejec G, Božikov K, Podnar S. Validation of preoperative nerve conduction studies by intraoperative studies in patients with ulnar neuropathy at the elbow. Clin Neurophysiol. 2016;127 (12):3499-3505. doi:10.1016/j.clinph.2016.09.018

66. Pelosi L, Tse DMY, Mulroy E, Chancellor AM, Boland MR. Ulnar neuropathy with abnormal non-localizing electrophysiology: clinical, electrophysiological and ultrasound findings. Clin Neurophysiol. 2018;129(10):2155-2161. doi:10.1016/j. clinph.2018.07.020

67. Deeg J, Loizides A, Löscher W, Zangerle A, Gruber H. Cyclingrelated compressive neuropathy of the deep ulnar motor branch in the hand: is sonography a valid tool? Ultrasound Med Biol. 2021;47(7):1970-1975. doi:10.1016/j.ultrasmedbio.2021.02.022

68. Wang GH, Mao T, Chen YL, et al. An intraneural ganglion cyst of the ulnar nerve at the wrist: a case report and literature review. $J$ Int Med Res. 2021;49(1):300060520982701. doi:10.1177/ 0300060520982701

69. Monacelli G, Rizzo MI, Spagnoli AM, Monarca C, Scuderi N. Ulnar artery thrombosis and nerve entrapment at Guyon's canal: our diagnostic and therapeutic algorithm. Vivo. 2010;24 (5):779-782.

70. Kerasnoudis A, Ntasiou P, Ntasiou E. Prognostic value of nerve ultrasound and electrophysiological findings in Saturday night palsy. J Neuroimaging. 2017;27(4):428-432. doi:10.1111/jon.12414

71. Al-Omari AA, Rusan M, Obeidat O, Almomani Z, Albustami IS, Alrawashdeh MA. Spontaneous full recovery of high radial nerve palsy following closed reduction and percutaneous pinning of Gartland iv supracondylar fracture: a case report. Am J Case Rep. 2021;22:e930277. doi:10.12659/ajcr.930277

72. Iskender Ö, Özkan O, Leblebicioğlu G, Ozçakar L. Ultrasound imaging for complete injury of the posterior interosseous nerve after forearm surgery. Am J Phys Med Rehabil. 2019;98(6):e66. doi:10.1097/phm.0000000000001056

73. Seki Y. Posterior interosseous nerve palsy caused by a ganglion: conservative treatment with ultrasound-guided needle aspiration. J Ultrason. 2017;17(68):73-75. doi:10.15557/JoU.2017.0010

74. Erol B, Cakir T, Kose O, Ozyurek S. Radial nerve entrapment caused by a ganglion cyst at the elbow: treatment with ultrasound-guided aspiration. Am J Phys Med Rehabil. 2014;93 (11):e6-7. doi:10.1097/phm.0000000000000153

75. Loizides A, Peer S, Ostermann S, Henninger B, StampferKountchev M, Gruber H. Unusual functional compression of the deep branch of the radial nerve by a vascular branch (leash of Henry): ultrasonographic appearance. Rofo. 2011;183 (2):163-166. doi:10.1055/s-0029-1245738

76. Narayan S, Ahluwalia VV, Saharan PS, Gupta AK. Intraosseous Lipoma of the proximal radius with extra osseous extension leading to posterior interosseous nerve compression: HRUS Diagnosis. J Orthop Case Rep. 2016;6(3):56-58. doi:10.13107/ jocr.2250-0685.506

77. Xiao TG, Cartwright MS. Ultrasound in the evaluation of radial neuropathies at the elbow. Front Neurol. 2019;10:216. doi:10.3389/fneur.2019.00216

78. Tzeng CY, Lee TS, Chen IC. Superficial radial nerve compression caused by a parosteal lipoma of proximal radius: a case report. Hand Surg. 2005;10(2-3):293-296. doi:10.1142/ s0218810405002851
79. Rodriguez Miralles J, Natera Cisneros L, Escolà A, Fallone JC, Cots M, Espiga X. Type A ganglion cysts of the radiocapitellar joint may involve compression of the superficial radial nerve. Orthop Traumatol Surg Res. 2016;102(6):791-794. doi:10.1016/ j.otsr.2016.05.014

80. Oz O, Yücel M, Ulaş U, Eroğlu E, Odabaşi Z. Superficial radial neuropathy and brachioradial motor nerve palsy associated with proximal radius osteochondroma. Neurol Neurochir Pol. 2010;44 (2):208-210. doi:10.1016/s0028-3843(14)60013-x

81. Kerasnoudis A, Pitarokoili K, Behrendt V, Gold R, Yoon MS. Cross sectional area reference values for sonography of peripheral nerves and brachial plexus. Clin Neurophysiol. 2013;124 (9):1881-1888. doi:10.1016/j.clinph.2013.03.007

82. Poage C, Roth C, Scott B. Peroneal nerve palsy: evaluation and management. J Am Acad Orthop Surg. 2016;24(1):1-10. doi:10.5435/jaaos-d-14-00420

83. Lee H, Brekelmans GJF, Visser LH. Quantitative assessment of nerve echogenicity as an additional tool for evaluation of common fibular neuropathy. Clin Neurophysiol. 2016;127 (1):874-879. doi:10.1016/j.clinph.2015.03.019

84. Kim DH, Murovic JA, Tiel RL, Kline DG. Management and outcomes in 318 operative common peroneal nerve lesions at the Louisiana state university health sciences center. Neurosurgery. 2004;54(6):1421. doi:10.1227/01. neu.0000124752.40412.03

85. Hobson-Webb LD, Juel VC. Common entrapment neuropathies. Continuum. 2017;23(2):487-511. doi:10.1212/ con.0000000000000452

86. Simon N, Kiernan M. Common peroneal neuropathy and cancer. Intern Med J. 2012;42:837. doi:10.1111/j.14455994.2012.02836.x

87. Visser LH. High-resolution sonography of the common peroneal nerve: detection of intraneural ganglia. Neurology. 2006;67 (8):1473-1475. doi:10.1212/01.wnl.0000240070.98910.bc

88. Stewart JD. Foot drop: where, why and what to do? Pract Neurol. 2008;8(3):158-169. doi:10.1136/jnnp.2008.149393

89. Fantino O. Role of ultrasound in posteromedial tarsal tunnel syndrome: 81 cases. $J$ Ultrasound. 2014;17(2):99-112. doi:10.1007/s40477-014-0082-9

90. Sanchez JE, Conkling N, Labropoulos N. Compression syndromes of the popliteal neurovascular bundle due to Baker cyst. $J \quad$ Vasc Surg. 2011;54(6):1821-1829. doi:10.1016/j. jvs.2011.07.079

91. Gruber L, Loizides A, Klien S, et al. A rare case of an acute soleus arcade syndrome complicated by a ganglion cyst: diagnosis by dynamic ultrasound. Med Ultrason. 2017;19(4):447-450. doi: $10.11152 / \mathrm{mu}-1003$

92. Williams EH, Rosson GD, Hagan RR, Hashemi SS, Dellon AL. Soleal sling syndrome (proximal tibial nerve compression): results of surgical decompression. Plast Reconstr Surg. 2012;129(2):454-462. doi:10.1097/PRS.0b013e31823aeb21

93. Simon NG, Kliot M. Diffusion weighted MRI and tractography for evaluating peripheral nerve degeneration and regeneration. Neural Regen Res. 2014;9(24):2122-2124. doi:10.4103/16735374.147941

94. Wilbourn AJ. The electrodiagnostic examination with peripheral nerve injuries. Clin Plast Surg. 2003;30(2):139-154. doi:10.1016/ s0094-1298(02)00099-8

95. Simon NG, Spinner RJ, Kline DG, Kliot M. Advances in the neurological and neurosurgical management of peripheral nerve trauma. J Neurol Neurosurg Psychiatry. 2016;87(2):198-208. doi:10.1136/jnnp-2014-310175

96. Omejec G, Podnar S. Contribution of ultrasonography in evaluating traumatic lesions of the peripheral nerves. Neurophysiol Clin. 2020;50(2):93-101. doi:10.1016/j.neucli.2020.01.007 
97. Padua L, Di Pasquale A, Liotta G, et al. Ultrasound as a useful tool in the diagnosis and management of traumatic nerve lesions. Clin Neurophysiol. 2013;124(6):1237-1243. doi:10.1016/j. clinph.2012.10.024

98. Simon NG, Ralph JW, Lomen-Hoerth C, et al. Quantitative ultrasound of denervated hand muscles. Muscle Nerve. 2015;52 (2):221-230. doi:10.1002/mus.24519

99. Hobson-Webb LD, Walker FO. Traumatic neuroma diagnosed by ultrasonography. Arch Neurol. 2004;61(8):1322-1323. doi:10.1001/archneur.61.8.1322

100. Erra C, Granata G, Liotta G, et al. Ultrasound diagnosis of bony nerve entrapment: case series and literature review. Muscle Nerve. 2013;48(3):445-450. doi:10.1002/mus.23845

101. Bodner G, Buchberger W, Schocke M, et al. Radial nerve palsy associated with humeral shaft fracture: evaluation with US-initial experience. Radiology. 2001;219(3):811-816. doi:10.1148/radiology.219.3.r01jn09811

102. Gofeld M, Bristow SJ, Chiu S, Kliot M. Preoperative ultrasound-guided mapping of peripheral nerves. J Neurosurg. 2013;119(3):709-713. doi:10.3171/2013.5.Jns122243

103. Koenig RW, Schmidt TE, Heinen CP, et al. Intraoperative high-resolution ultrasound: a new technique in the management of peripheral nerve disorders. J Neurosurg. 2011;114(2):514-521. doi:10.3171/2010.9.Jns10464

104. Peer S, Harpf C, Willeit J, Piza-Katzer H, Bodner G. Sonographic evaluation of primary peripheral nerve repair. J Ultrasound Med. 2003;22(12):1317-1322. doi:10.7863/jum.2003.22.12.1317

105. Eppenberger P, Andreisek G, Chhabra A. Magnetic resonance neurography: diffusion tensor imaging and future directions. Neuroimaging Clin N Am. 2014;24(1):245-256. doi:10.1016/j. nic.2013.03.031

106. Simon NG, Narvid J, Cage T, et al. Visualizing axon regeneration after peripheral nerve injury with magnetic resonance tractography. Neurology. 2014;83(15):1382-1384. doi:10.1212/ wnl.0000000000000861

107. Zaidman CM, Harms MB, Pestronk A. Ultrasound of inherited vs. acquired demyelinating polyneuropathies. J Neurol. 2013;260 (12):3115-3121. doi:10.1007/s00415-013-7123-8

108. Padua L, Granata G, Sabatelli M, et al. Heterogeneity of root and nerve ultrasound pattern in CIDP patients. Clin Neurophysiol. 2014;125(1):160-165. doi:10.1016/j.clinph.2013.07.023

109. Sugimoto T, Ochi K, Hosomi N, et al. Ultrasonographic nerve enlargement of the median and ulnar nerves and the cervical nerve roots in patients with demyelinating Charcot-Marie-Tooth disease: distinction from patients with chronic inflammatory demyelinating polyneuropathy. $J$ Neurol. 2013;260 (10):2580-2587. doi:10.1007/s00415-013-7021-0

110. Carandang MAE, Takamatsu N, Nodera H, et al. Velocity of intraneural blood flow is increased in inflammatory neuropathies: sonographic observation. J Neurol Neurosurg Psychiatry. 2017;88 (5):455-457. doi:10.1136/jnnp-2016-314547

111. Neubauer C, Gruber H, Bäuerle J, Egger K. Ultrasonography of Multifocal acquired demyelinating sensory and motor neuropathy (MADSAM). Clin Neuroradiol. 2015;25(4):423-425. doi:10.1007/s00062-014-0364-9

112. Simon NG, Kiernan MC. Precise correlation between structural and electrophysiological disturbances in MADSAM neuropathy. Neuromuscul Disord. 2015;25(11):904-907. doi:10.1016/j. nmd.2015.07.012

113. Scheidl E, Böhm J, Simó M, et al. Ultrasonography of MADSAM neuropathy: focal nerve enlargements at sites of existing and resolved conduction blocks. Neuromuscul Disord. 2012;22 (7):627-631. doi:10.1016/j.nmd.2012.03.005
114. Tanaka K, Ota N, Harada Y, Wada I, Suenaga T. Normalization of sonographical multifocal nerve enlargements in a MADSAM patient following a good clinical response to intravenous immunoglobulin. Neuromuscul Disord. 2016;26(9):619-623. doi:10.1016/j.nmd.2016.06.008

115. Herraets IJT, Goedee HS, Telleman JA, et al. Nerve ultrasound for diagnosing chronic inflammatory neuropathy: a multicenter validation study. Neurology. 2020;95(12):e1745-e1753. doi:10.1212/wnl.0000000000010369

116. Stino AM, Naddaf E, Dyck PJ, Dyck PJB. Chronic inflammatory demyelinating polyradiculoneuropathy-Diagnostic pitfalls and treatment approach. Muscle Nerve. 2021;63(2):157-169. doi:10.1002/mus. 27046

117. Grimm A, Décard BF, Axer H, Fuhr P. The Ultrasound pattern sum score - UPSS. A new method to differentiate acute and subacute neuropathies using ultrasound of the peripheral nerves. Clin Neurophysiol. 2015;126(11):2216-2225. doi:10.1016/j. clinph.2015.01.011

118. Jang JH, Cho CS, Yang KS, Seok HY, Kim BJ. Pattern analysis of nerve enlargement using ultrasonography in chronic inflammatory demyelinating polyneuropathy. Clin Neurophysiol. 2014;125 (9):1893-1899. doi:10.1016/j.clinph.2013.12.115

119. Telleman JA, Grimm A, Goedee S, Visser LH, Zaidman CM. Nerve ultrasound in polyneuropathies. Muscle Nerve. 2018;57 (5):716-728. doi:10.1002/mus.26029

120. Padua L, Martinoli C, Pazzaglia C, et al. Intra- and internerve cross-sectional area variability: new ultrasound measures. Muscle Nerve. 2012;45(5):730-733. doi:10.1002/mus.23252

121. Goedee HS, Brekelmans GJ, Visser LH. Multifocal enlargement and increased vascularization of peripheral nerves detected by sonography in CIDP: a pilot study. Clin Neurophysiol. 2014;125 (1):154-159. doi:10.1016/j.clinph.2013.05.025

122. Matsuoka N, Kohriyama T, Ochi K, et al. Detection of cervical nerve root hypertrophy by ultrasonography in chronic inflammatory demyelinating polyradiculoneuropathy. $J$ Neurol Sci. 2004;219(1-2):15-21. doi:10.1016/j.jns.2003.11.011

123. Grimm A, Vittore D, Schubert V, et al. Ultrasound aspects in therapy-naive CIDP compared to long-term treated CIDP. $J$ Neurol. 2016;263(6):1074-1082. doi:10.1007/s00415-0168100-9

124. Fionda L, Di Pasquale A, Morino S, et al. Changes of clinical, neurophysiological and nerve ultrasound characteristics in CIDP over time: a 3-year follow-up. J Neurol. 2021:27. doi:10.1007/ s00415-021-10485-x

125. Kerasnoudis A, Pitarokoili K, Behrendt V, Gold R, Yoon MS. Correlation of nerve ultrasound, electrophysiological and clinical findings in chronic inflammatory demyelinating polyneuropathy. J Neuroimaging. 2015;25(2):207-216. doi:10.1111/jon.12079

126. Kerasnoudis A, Pitarokoili K, Gold R, Yoon MS. Nerve Ultrasound and Electrophysiology for Therapy Monitoring in Chronic Inflammatory Demyelinating Polyneuropathy. $J$ Neuroimaging. 2015;25(6):931-939. doi:10.1111/jon.12279

127. Gallardo E, Sedano MJ, Orizaola P, et al. Spinal nerve involvement in early Guillain-Barré syndrome: a clinicoelectrophysiological, ultrasonographic and pathological study. Clin Neurophysiol. 2015;126(4):810-819. doi:10.1016/j. clinph.2014.06.051

128. Grimm A, Décard BF, Axer H. Ultrasonography of the peripheral nervous system in the early stage of Guillain-Barré syndrome. J Peripher Nerv Syst. 2014;19(3):234-241. doi:10.1111/jns.12091

129. Grimm A, Décard BF, Schramm A, et al. Ultrasound and electrophysiologic findings in patients with Guillain-Barré syndrome at disease onset and over a period of six months. Clin Neurophysiol. 2016;127(2):1657-1663. doi:10.1016/j.clinph.2015.06.032 
130. Mori A, Nodera H, Takamatsu N, et al. Sonographic evaluation of peripheral nerves in subtypes of Guillain-Barré syndrome. J Neurol Sci. 2016;364:154-159. doi:10.1016/j.jns.2016.03.042

131. Razali SNO, Arumugam T, Yuki N, Rozalli FI, Goh KJ, Shahrizaila N. Serial peripheral nerve ultrasound in GuillainBarré syndrome. Clin Neurophysiol. 2016;127(2):1652-1656. doi:10.1016/j.clinph.2015.06.030

132. Hsueh HW, Chang KC, Chao CC, Hsieh ST, Pilot A. Study on Serial nerve ultrasound in miller fisher syndrome. Front Neurol. 2020;11:865. doi:10.3389/fneur.2020.00865

133. Yeh WZ, Dyck PJ, Van Den Berg LH, Kiernan MC, Taylor BV. Multifocal motor neuropathy: controversies and priorities. Review. J Neurol Neurosurg Psychiatry. 2020;91(2):140-148. doi:10.1136/jnnp-2019-321532

134. Tracy JA, Taylor BV, Kiernan M, et al. Nerve Pathology distinguishes focal motor chronic inflammatory demyelinating polyradiculoneuropathy from multifocal motor neuropathy. J Clin Neuromuscul Dis. 2020;22(1):1-10. doi:10.1097/ cnd.0000000000000279

135. Kiernan MC, Guglielmi JM, Kaji R, Murray NM, Bostock H. Evidence for axonal membrane hyperpolarization in multifocal motor neuropathy with conduction block. Brain. 2002;125(Pt 3):664-675. doi:10.1093/brain/awf041

136. Simon N, Ayer G, Lomen-Hoerth C. Is IVIg therapy warranted in progressive lower motor neuron syndromes without conduction block? Neurology. 2013;81. doi:10.1212/01.wnl.0000437301. 28441.7e

137. Beekman R, van den Berg LH, Franssen H, Visser LH, van Asseldonk JT, Wokke JH. Ultrasonography shows extensive nerve enlargements in multifocal motor neuropathy. Neurology. 2005;65(2):305-307. doi:10.1212/01.wnl.0000169179.67764.30

138. Grimm A, Décard BF, Athanasopoulou I, Schweikert K, Sinnreich M, Axer H. Nerve ultrasound for differentiation between amyotrophic lateral sclerosis and multifocal motor neuropathy. $J$ Neurol. 2015;262(4):870-880. doi:10.1007/ s00415-015-7648-0

139. Loewenbrück KF, Liesenberg J, Dittrich M, et al. Nerve ultrasound in the differentiation of multifocal motor neuropathy (MMN) and amyotrophic lateral sclerosis with predominant lower motor neuron disease (ALS/LMND). J Neurol. 2016;263 (1):35-44. doi:10.1007/s00415-015-7927-9

140. Loewenbrück KF, Werner R, Günther R, et al. One nerve suffices: a clinically guided nerve ultrasound protocol for the differentiation of multifocal motor neuropathy (MMN) and amyotrophic lateral sclerosis (ALS). J Neurol. 2021;268(4):1495-1507. doi:10.1007/s00415-020-10323-6

141. Merola A, Rosso M, Romagnolo A, Peci E, Cocito D. Peripheral nerve ultrasonography in chronic inflammatory demyelinating polyradiculoneuropathy and multifocal motor neuropathy: correlations with clinical and neurophysiological data. Neurol Res Int. 2016;2016:9478593. doi:10.1155/2016/9478593

142. Kerasnoudis A, Pitarokoili K, Behrendt V, Gold R, Yoon MS. Multifocal motor neuropathy: correlation of nerve ultrasound, electrophysiological, and clinical findings. J Peripher Nerv Syst. 2014;19(2):165-174. doi:10.1111/jns5.12067

143. Rattay TW, Winter N, Décard BF, et al. Nerve ultrasound as follow-up tool in treated multifocal motor neuropathy. Eur J Neurol. 2017;24(9):1125-1134. doi:10.1111/ene.13344

144. Goedee HS, Notermans NC, Visser LH, et al. Neuropathy associated with immunoglobulin $\mathrm{M}$ monoclonal gammopathy: a combined sonographic and nerve conduction study. Muscle Nerve. 2019;60(3):263-270. doi:10.1002/mus.26626

145. Garg N, Park SB, Howells J, et al. Anti-MAG neuropathy: role of IgM antibodies, the paranodal junction and juxtaparanodal potassium channels. Clin Neurophysiol. 2018;129(10):2162-2169. doi:10.1016/j.clinph.2018.07.021
146. Lucchetta M, Padua L, Granata G, et al. Nerve ultrasound findings in neuropathy associated with anti-myelin-associated glycoprotein antibodies. Eur J Neurol. 2015;22(1):193-202. doi:10.1111/ene. 12554

147. Piccione EA, Engelstad J, Dyck PJ, Mauermann ML, Dispenzieri A, Dyck PJ. Nerve pathologic features differentiate POEMS syndrome from CIDP. Acta Neuropathol Commun. 2016;4(1):116. doi:10.1186/s40478-016-0389-1

148. Lucchetta M, Pazzaglia C, Granata G, Briani C, Padua L. Ultrasound evaluation of peripheral neuropathy in POEMS syndrome. Muscle Nerve. 2011;44(6):868-872. doi:10.1002/mus.22258

149. Gstoettner C, Mayer JA, Rassam S, et al. Neuralgic amyotrophy: a paradigm shift in diagnosis and treatment. J Neurol Neurosurg Psychiatry. 2020;91(8):879-888. doi:10.1136/jnnp-2020-323164

150. van Rosmalen M, Lieba-Samal D, Pillen S, van Alfen N. Ultrasound of peripheral nerves in neuralgic amyotrophy. Muscle Nerve. 2019;59(1):55-59. doi:10.1002/mus.26322

151. Arányi Z, Csillik A, DéVay K, et al. Ultrasonography in neuralgic amyotrophy: sensitivity, spectrum of findings, and clinical correlations. Muscle Nerve. 2017;56(6):1054-1062. doi:10.1002/ mus. 25708

152. Arányi Z, Csillik A, Dévay K, et al. Ultrasonographic identification of nerve pathology in neuralgic amyotrophy: enlargement, constriction, fascicular entwinement, and torsion. Muscle Nerve. 2015;52(4):503-511. doi:10.1002/mus.24615

153. Leupold D, Felbecker A, Tettenborn B, Hundsberger T. Nerve Ultrasound as a decisive tool in nonsystemic vasculitic neuropathy: a case report. Case Rep Neurol. 2016;8(2):108-114. doi:10.1159/000446314

154. Grimm A, Décard BF, Bischof A, Axer H. Ultrasound of the peripheral nerves in systemic vasculitic neuropathies. $J$ Neurol Sci. 2014;347(1-2):44-49. doi:10.1016/j.jns.2014.09.017

155. Goedee HS, van der Pol WL, van Asseldonk JH, et al. Nerve sonography to detect peripheral nerve involvement in vasculitis syndromes. Neurol Clin Pract. 2016;6(4):293-303. doi:10.1212/ cpj.0000000000000258

156. Ito $T$, Kijima $M$, Watanabe $T$, Sakuta $M$, Nishiyama $K$. Ultrasonography of the tibial nerve in vasculitic neuropathy. Muscle Nerve. 2007;35(3):379-382. doi:10.1002/mus.20673

157. Üçeyler N, Schäfer KA, Mackenrodt D, Sommer C, Müllges W. High-resolution ultrasonography of the superficial peroneal motor and sural sensory nerves may be a non-invasive approach to the diagnosis of vasculitic neuropathy. Front Neurol. 2016;7:48. doi:10.3389/fneur.2016.00048

158. Noto Y, Shiga K, Tsuji Y, et al. Nerve ultrasound depicts peripheral nerve enlargement in patients with genetically distinct Charcot-Marie-Tooth disease. J Neurol Neurosurg Psychiatry. 2015;86(4):378-384. doi:10.1136/jnnp-2014-308211

159. Pazzaglia C, Minciotti I, Coraci D, Briani C, Padua L. Ultrasound assessment of sural nerve in Charcot-Marie-Tooth 1A neuropathy. Clin Neurophysiol. 2013;124(8):1695-1699. doi:10.1016/j. clinph.2013.02.020

160. Zanette G, Fabrizi GM, Taioli F, et al. Nerve ultrasound findings differentiate Charcot-Marie-Tooth disease (CMT) 1A from other demyelinating CMTs. Clin Neurophysiol. 2018;129 (11):2259-2267. doi:10.1016/j.clinph.2018.08.016

161. Yiu EM, Brockley CR, Lee KJ, et al. Peripheral nerve ultrasound in pediatric Charcot-Marie-Tooth disease type 1A. Neurology. 2015;84 (6):569-574. doi:10.1212/wnl.0000000000001236

162. Zanette G, Tamburin S, Taioli F, et al. Nerve size correlates with clinical severity in Charcot-Marie-Tooth disease 1A. Muscle Nerve. 2019;60(6):744-748. doi:10.1002/mus.26688

163. Cartwright MS, Brown ME, Eulitt P, Walker FO, Lawson VH, Caress JB. Diagnostic nerve ultrasound in Charcot-Marie-Tooth disease type 1B. Muscle Nerve. 2009;40(1):98-102. doi:10.1002/ mus. 21292 
164. Fabrizi GM, Tamburin S, Cavallaro T, et al. The spectrum of Charcot-Marie-Tooth disease due to myelin protein zero: an electrodiagnostic, nerve ultrasound and histological study. Clin Neurophysiol. 2018;129(1):21-32. doi:10.1016/j. clinph.2017.09.117

165. Padua L, Coraci D, Lucchetta M, et al. Different nerve ultrasound patterns in charcot-Marie-tooth types and hereditary neuropathy with liability to pressure palsies. Muscle Nerve. 2018;57(1):E18e23. doi:10.1002/mus.25766

166. Schreiber S, Oldag A, Kornblum C, et al. Sonography of the median nerve in CMT1A, CMT2A, CMTX, and HNPP. Muscle Nerve. 2013;47(3):385-395. doi:10.1002/mus.23681

167. Kojima Y, Noto YI, Tsuji Y, et al. Charcot-Marie-Tooth disease type 1A: longitudinal change in nerve ultrasound parameters. Muscle Nerve. 2020;62(6):722-727. doi:10.1002/mus.27068

168. Shahrizaila N, Noto Y, Simon NG, et al. Quantitative muscle ultrasound as a biomarker in Charcot-Marie-Tooth neuropathy. Clin Neurophysiol. 2017;128(1):227-232. doi:10.1016/j. clinph.2016.11.010

169. Goedee SH, Brekelmans GJ, van den Berg LH, Visser LH. Distinctive patterns of sonographic nerve enlargement in Charcot-Marie-Tooth type 1A and hereditary neuropathy with pressure palsies. Clin Neurophysiol. 2015;126(7):1413-1420. doi:10.1016/j.clinph.2014.08.026

170. Bayrak AO, Bayrak IK, Battaloglu E, Ozes B, Yildiz O, Onar MK. Ultrasonographic findings in hereditary neuropathy with liability to pressure palsies. Neurol Res. 2015;37 (2):106-111. doi:10.1179/1743132814y.0000000411

171. Beekman R, Visser LH. Sonographic detection of diffuse peripheral nerve enlargement in hereditary neuropathy with liability to pressure palsies. J Clin Ultrasound. 2002;30(7):433-436. doi:10.1002/jcu. 10090

172. Ginanneschi F, Filippou G, Giannini F, et al. Sonographic and electrodiagnostic features of hereditary neuropathy with liability to pressure palsies. J Peripher Nerv Syst. 2012;17(4):391-398. doi:10.1111/j.1529-8027.2012.00437.x

173. Granata G, Luigetti M, Coraci D, et al. Ultrasound evaluation in transthyretin-related amyloid neuropathy. Muscle Nerve. 2014;50 (3):372-376. doi:10.1002/mus.24168

174. Podnar S, Sarafov S, Tournev I, Omejec G, Zidar J. Peripheral nerve ultrasonography in patients with transthyretin amyloidosis. Clin Neurophysiol. 2017;128(4):505-511. doi:10.1016/j. clinph.2017.01.013

175. Salvalaggio A, Coraci D, Cacciavillani M, et al. Nerve ultrasound in hereditary transthyretin amyloidosis: red flags and possible progression biomarkers. $J$ Neurol. 2021;268(1):189-198. doi:10.1007/s00415-020-10127-8

176. Dupré M, Hermann R, Froment Tilikete C. Update on Cerebellar Ataxia with Neuropathy and Bilateral Vestibular Areflexia Syndrome (CANVAS). The Cerebellum. 2020;2020. doi:10.1007/s12311-020-01192-w

177. Pelosi L, Mulroy E, Leadbetter R, et al. Peripheral nerves are pathologically small in cerebellar ataxia neuropathy vestibular areflexia syndrome: a controlled ultrasound study. Eur J Neurol. 2018;25(4):659-665. doi:10.1111/ene.13563

178. Leadbetter R, Weatherall M, Pelosi L. Nerve ultrasound as a diagnostic tool for sensory neuronopathy in spinocerebellar ataxia syndrome. Clin Neurophysiol. 2019;130(4):568-572. doi:10.1016/j.clinph.2018.12.010

179. Bhandari J, Thada PK, Samanta D. Spinocerebellar Ataxia. StatPearls. StatPearls Publishing; 2015.

180. Mulroy E, Pelosi L, Leadbetter R, et al. Peripheral nerve ultrasound in Friedreich ataxia. Muscle Nerve. 2018;57(5):852-856. doi:10.1002/mus.26012
181. Borire AA, Issar T, Kwai NC, et al. Correlation between markers of peripheral nerve function and structure in type 1 diabetes. Diabetes Metab Res Rev. 2018;34(7):e3028. doi:10.1002/dmrr.3028

182. Riazi S, Bril V, Perkins BA, et al. Can ultrasound of the tibial nerve detect diabetic peripheral neuropathy? A cross-sectional study. Diabetes Care. 2012;35(12):2575-2579. doi:10.2337/dc12-0739

183. Lee D, Dauphinée DM. Morphological and functional changes in the diabetic peripheral nerve: using diagnostic ultrasound and neurosensory testing to select candidates for nerve decompression. J Am Podiatr Med Assoc. 2005;95(5):433-437. doi: $10.7547 / 0950433$

184. Watanabe $\mathrm{T}$, Ito $\mathrm{H}$, Sekine $\mathrm{A}$, et al. Sonographic evaluation of the peripheral nerve in diabetic patients: the relationship between nerve conduction studies, echo intensity, and cross-sectional area. JUltrasound Med. 2010;29(5):697-708. doi:10.7863/jum.2010.29.5.697

185. Singh K, Gupta K, Kaur S. High resolution ultrasonography of the tibial nerve in diabetic peripheral neuropathy. $J$ Ultrason. 2017;17(71):246-252. doi:10.15557/JoU.2017.0036

186. Breiner A, Qrimli M, Ebadi H, et al. Peripheral nerve high-resolution ultrasound in diabetes. Muscle Nerve. 2017;55 (2):171-178. doi:10.1002/mus.25223

187. Issar T, Tummanapalli SS, Borire AA, et al. Impact of the metabolic syndrome on peripheral nerve structure and function in type 2 diabetes. Eur J Neurol. 2021;28(6):2074-2082. doi:10.1111/ ene. 14805

188. Dikici AS, Ustabasioglu FE, Delil S, et al. Evaluation of the Tibial nerve with shear-wave elastography: a potential sonographic method for the diagnosis of diabetic peripheral neuropathy. Radiology. 2017;282(2):494-501. doi:10.1148/ radiol.2016160135

189. Briani C, Campagnolo M, Lucchetta M, et al. Ultrasound assessment of oxaliplatin-induced neuropathy and correlations with neurophysiologic findings. Eur J Neurol. 2013;20(1):188-192. doi:10.1111/j.1468-1331.2012.03852.x

190. Lycan TW, Hsu FC, Ahn CS, et al. Neuromuscular ultrasound for taxane peripheral neuropathy in breast cancer. Muscle Nerve. 2020;61(5):587-594. doi:10.1002/mus.26833

191. World Helath Organization. Global Health Observatory (GHO) data, Leprosy; 2016. Available from: http://wwwwhoint/gho/ neglected_diseases/leprosy/en/. Accessed September 8, 2017.

192. Bathala L, Kumar K, Pathapati R, Jain S, Visser LH. Ulnar neuropathy in Hansen disease: clinical, high-resolution ultrasound and electrophysiologic correlations. J Clin Neurophysiol. 2012;29 (2):190-193. doi:10.1097/WNP.0b013e31824d969c

193. Chaduvula MV, Visser LH, Suneetha S, et al. High-Resolution sonography as an additional diagnostic and prognostic tool to monitor disease activity in leprosy: a two-year prospective study. Ultraschall Med. 2018;39(1):80-89. doi:10.1055/s-0042-108430

194. Elias J, Nogueira-Barbosa MH, Feltrin LT, et al. Role of ulnar nerve sonography in leprosy neuropathy with electrophysiologic correlation. J Ultrasound Med. 2009;28(9):1201-1209. doi:10.7863/jum.2009.28.9.1201

195. Martinoli C, Derchi LE, Bertolotto M, et al. US and MR imaging of peripheral nerves in leprosy. Skeletal Radiol. 2000;29 (3):142-150. doi:10.1007/s002560050584

196. Alshaikh NM, Martinez JP, Pitt MC. Perception of pain during electromyography in children: a prospective study. Muscle Nerve. 2016;54(3):422-426. doi:10.1002/mus.25069

197. VanHorn TA, Cartwright MS. Neuromuscular Ultrasound in the Pediatric Population. Diagnostics. 2020;10(12). doi:10.3390/ diagnostics 10121012

198. Mandeville R, Wali A, Park C, Groessl E, Walker FO, Cartwright MS. Cost-effectiveness of neuromuscular ultrasound in focal neuropathies. Neurology. 2019;92(23):e2674-e2678. doi:10.1212/wnl.0000000000007602 
199. Maurits NM, Beenakker EA, van Schaik DE, Fock JM, van der Hoeven JH. Muscle ultrasound in children: normal values and application to neuromuscular disorders. Ultrasound Med Biol. 2004;30(8):1017-1027. doi:10.1016/j.ultrasmedbio.2004.05.013

200. Wang W, Wang Q. Sonographic measurements of normal C5-C8 nerve roots in children. Muscle Nerve. 2020;61(5):649-653. doi:10.1002/mus.26826

201. Druzhinin D, Naumova E, Nikitin S. Nerve ultrasound normal values in children and young adults. Muscle Nerve. 2019;60 (6):757-761. doi:10.1002/mus.26715

202. Cartwright MS, Mayans DR, Gillson NA, Griffin LP, Walker FO. Nerve cross-sectional area in extremes of age. Muscle Nerve. 2013;47(6):890-893. doi:10.1002/mus.23718

203. Bäumer T, Bühring N, Schelle T, Münchau A, Muschol N. Nerve ultrasound in clinical management of carpal tunnel syndrome in mucopolysaccharidosis. Dev Med Child Neurol. 2016;58 (11):1172-1179. doi:10.1111/dmcn.13127

204. Okechi H, Dimostheni A, Kerscher SR, et al. Fibrolipomatous hamartomas of the median nerve in infancy and early childhood-imaging hallmarks, symptomatology, and treatment. Eur J Pediatr. 2018;177(4):567-573. doi:10.1007/s00431-0183100-7

205. Cartwright MS, Griffin LP, Dowlen H, et al. A randomized trial of diagnostic ultrasound to improve outcomes in focal neuropathies. Muscle Nerve. 2015;52(5):746-753. doi:10.1002/mus.24884

206. Rahmani N, Mohseni-Bandpei MA, Vameghi R, Salavati M, Abdollahi I. Application of ultrasonography in the assessment of skeletal muscles in children with and without neuromuscular disorders: a systematic review. Ultrasound Med Biol. 2015;41 (9):2275-2283. doi:10.1016/j.ultrasmedbio.2015.04.027

207. Doumouchtsis SK, Arulkumaran S. Are all brachial plexus injuries caused by shoulder dystocia? Obstet Gynecol Surv. 2009;64 (9):615-623. doi:10.1097/OGX.0b013e3181b27a3a

208. Kevin Chung LJ-SY, John M. Practical Management of Pediatric and Adult Brachial Plexus Palsies. 1st ed. Saunders; 2011.

209. Somashekar DK, Di Pietro MA, Joseph JR, Yang LJ, Parmar HA. Utility of ultrasound in noninvasive preoperative workup of neonatal brachial plexus palsy. Pediatr Radiol. 2016;46(5):695-703. doi:10.1007/s00247-015-3524-4

210. Rardin BP, Verenes MP, Cartwright MS. Ultrasound first for pediatric patients in an electrodiagnostic laboratory. $J$ Clin Neurophysiol. 2020. doi:10.1097/wnp.0000000000000737

211. Paganoni S, Macklin EA, Lee A, et al. Diagnostic timelines and delays in diagnosing amyotrophic lateral sclerosis (ALS). Amyotroph Lateral Scler Frontotemporal Degener. 2014;15(56):453-456. doi:10.3109/21678421.2014.903974

212. Chen A, Weimer L, Brannagan T, et al. Experience with the Awaji Island modifications to the ALS diagnostic criteria. Muscle Nerve. 2010;42(5):831-832. doi:10.1002/mus.21841

213. Kiernan MC, Vucic S, Cheah BC, et al. Amyotrophic lateral sclerosis. Lancet. 2011;377(9769):942-955. doi:10.1016/s01406736(10)61156-7

214. Turner MR, Hardiman O, Benatar M, et al. Controversies and priorities in amyotrophic lateral sclerosis. Lancet Neurol. 2013;12 (3):310-322. doi:10.1016/s1474-4422(13)70036-x

215. Turner MR, Talbot K. Mimics and chameleons in motor neurone disease. Pract Neurol. 2013;13(3):153-164. doi:10.1136/practneurol-2013-000557

216. Gawel M, Kuzma-Kozakiewicz M, Szmidt-Salkowska E, Kamińska A. Are we really closer to improving the diagnostic sensitivity in ALS patients with Awaji criteria? Amyotroph Lateral Scler Frontotemporal Degener. 2014;15(3-4):257-261. doi:10.3109/21678421.2014.887118
217. Higashihara M, Sonoo M, Imafuku I, et al. Fasciculation potentials in amyotrophic lateral sclerosis and the diagnostic yield of the Awaji algorithm. Muscle Nerve. 2012;45(2):175-182. doi:10.1002/mus.22299

218. Jang JS, Bae JS. AWAJI criteria are not always superior to the previous criteria: a meta-analysis. Muscle Nerve. 2015;51 (6):822-829. doi:10.1002/mus.24575

219. de Carvalho M, Dengler R, Eisen A, et al. Electrodiagnostic criteria for diagnosis of ALS. Clin Neurophysiol. 2008;119 (3):497-503. doi:10.1016/j.clinph.2007.09.143

220. Chiò A. ISIS Survey: an international study on the diagnostic process and its implications in amyotrophic lateral sclerosis. J Neurol. 1999;246:Iii1. doi:10.1007/bf03161081

221. Turner MR, Kiernan MC, Leigh PN, Talbot K. Biomarkers in amyotrophic lateral sclerosis. Lancet Neurol. 2009;8(1):94-109. doi:10.1016/s1474-4422(08)70293-x

222. Aggarwal S, Cudkowicz M. ALS drug development: reflections from the past and a way forward. Neurotherapeutics. 2008;5 (4):516-527. doi:10.1016/j.nurt.2008.08.002

223. Hannaford A, Pavey N, van den Bos M, et al. Diagnostic utility of gold coast criteria in amyotrophic lateral sclerosis. Ann Neurol. 2021;89(5):979-986. doi:10.1002/ana.26045

224. Carvalho MD, Swash M. Awaji diagnostic algorithm increases sensitivity of El Escorial criteria for ALS diagnosis. Amyotroph Lateral Scler. 2009;10(1):53-57. doi:10.1080/17482960802521126

225. Costa J, Swash M, de Carvalho M. Awaji criteria for the diagnosis of amyotrophic lateral sclerosis: asystematic review. Arch Neurol. 2012;69(11):1410-1416. doi:10.1001/archneurol.2012.254

226. Schrooten M, Smetcoren C, Robberecht W, Van Damme P. Benefit of the Awaji diagnostic algorithm for amyotrophic lateral sclerosis: a prospective study. Ann Neurol. 2011;70(1):79-83. doi:10.1002/ana.22380

227. Misawa S, Noto Y, Shibuya K, et al. Ultrasonographic detection of fasciculations markedly increases diagnostic sensitivity of ALS. Neurology. 2011;77(16):1532-1537. doi:10.1212/ WNL.0b013e318233b36a

228. Tsuji Y, Noto YI, Shiga K, Teramukai S, Nakagawa M, Mizuno T. A muscle ultrasound score in the diagnosis of amyotrophic lateral sclerosis. Clin Neurophysiol. 2017;128(6):1069-1074. doi:10.1016/j.clinph.2017.02.015

229. Juan W, Fang L, Qi W, et al. Muscle ultrasonography in the diagnosis of amyotrophic lateral sclerosis. Neurol Res. 2020;42 (6):458-462. doi:10.1080/01616412.2020.1738100

230. Martínez-Payá JJ, Del Baño-Aledo ME, Ríos-Díaz J, TemblFerrairó JI, Vázquez-Costa JF, Medina-Mirapeix F. Muscular Echovariation: a new biomarker in amyotrophic lateral sclerosis. Ultrasound Med Biol. 2017;43(6):1153-1162. doi:10.1016/j. ultrasmedbio.2017.02.002

231. Martínez-Payá JJ, Ríos-Díaz J, Medina-Mirapeix F, VázquezCosta JF, Del Baño-Aledo ME. Monitoring Progression of Amyotrophic Lateral Sclerosis Using Ultrasound Morpho-Textural Muscle Biomarkers: a Pilot Study. Ultrasound Med Biol. 2018;44(1):102-109. doi:10.1016/j. ultrasmedbio.2017.09.013

232. Cartwright MS, Walker FO, Griffin LP, Caress JB. Peripheral nerve and muscle ultrasound in amyotrophic lateral sclerosis. Muscle Nerve. 2011;44(3):346-351. doi:10.1002/mus.22035

233. Mori A, Nodera H, Takamatsu N, et al. Sonographic evaluation of cervical nerve roots in ALS and its clinical subtypes. $J$ Med Invest. 2016;63(1-2):54-57. doi:10.2152/jmi.63.54

234. Nodera H, Takamatsu N, Shimatani Y, et al. Thinning of cervical nerve roots and peripheral nerves in ALS as measured by sonography. Clin Neurophysiol. 2014;125(9):1906-1911. doi:10.1016/j.clinph.2014.01.033 
235. Schreiber S, Abdulla S, Debska-Vielhaber G, et al. Peripheral nerve ultrasound in amyotrophic lateral sclerosis phenotypes. Muscle Nerve. 2015;51(5):669-675. doi:10.1002/mus.24431

236. Noto YI, Garg N, Li T, et al. Comparison of cross-sectional areas and distal-proximal nerve ratios in amyotrophic lateral sclerosis. Muscle Nerve. 2018;58(6):777-783. doi:10.1002/mus.26301

237. Barnes SL, Simon NG. Clinical and research applications of neuromuscular ultrasound in amyotrophic lateral sclerosis. Degener Neurol Neuromuscul Dis. 2019;9:89-102. doi:10.2147/ dnnd.S215318

238. Schreiber S, Dannhardt-Stieger V, Henkel D, et al. Quantifying disease progression in amyotrophic lateral sclerosis using peripheral nerve sonography. Muscle Nerve. 2016;54(3):391-397. doi:10.1002/mus.25066

239. Tamburrini S, Solazzo A, Sagnelli A, et al. Amyotrophic lateral sclerosis: sonographic evaluation of dysphagia. Radiol Med. 2010;115(5):784-793. doi:10.1007/s11547-010-0523-2

240. Nakamori M, Hosomi N, Takaki S, et al. Tongue thickness evaluation using ultrasonography can predict swallowing function in amyotrophic lateral sclerosis patients. Clin Neurophysiol. 2016;127(2):1669-1674. doi:10.1016/j.clinph.2015.07.032

241. Mazzini L, Corrà T, Zaccala M, Mora G, Del Piano M, Galante M. Percutaneous endoscopic gastrostomy and enteral nutrition in amyotrophic lateral sclerosis. J Neurol. 1995;242 (10):695-698. doi:10.1007/bf00866922

242. Miller RG, Jackson CE, Kasarskis EJ, et al. Practice parameter update: the care of the patient with amyotrophic lateral sclerosis: drug, nutritional, and respiratory therapies (an evidence-based review): report of the Quality Standards Subcommittee of the American Academy of Neurology. Neurology. 2009;73 (15):1218-1226. doi:10.1212/WNL.0b013e3181bc0141

243. Noto YI, Simon N, Shibuya K, Matamala JM, Dharmadasa T, Kiernan MC. Dynamic muscle ultrasound identifies upper motor neuron involvement in amyotrophic lateral sclerosis. Amyotroph Lateral Scler Frontotemporal Degener. 2017;18(5-6):404-410. doi:10.1080/21678421.2017.1286355

244. Andersen PM, Abrahams S, Borasio GD, et al. EFNS guidelines on the clinical management of amyotrophic lateral sclerosis (MALS)-revised report of an EFNS task force. Eur J Neurol. 2012;19(3):360-375. doi:10.1111/j.1468-1331.2011.03501.x

245. Kleopa KA, Sherman M, Neal B, Romano GJ, Heiman-Patterson T. Bipap improves survival and rate of pulmonary function decline in patients with ALS. J Neurol Sci. 1999;164(1):82-88. doi:10.1016/s0022-510x(99)00045-3

246. Bourke SC, Tomlinson M, Williams TL, Bullock RE, Shaw PJ, Gibson GJ. Effects of non-invasive ventilation on survival and quality of life in patients with amyotrophic lateral sclerosis: a randomised controlled trial. Lancet Neurol. 2006;5 (2):140-147. doi:10.1016/s1474-4422(05)70326-4

247. Hiwatani Y, Sakata M, Miwa H. Ultrasonography of the diaphragm in amyotrophic lateral sclerosis: clinical significance in assessment of respiratory functions. Amyotroph Lateral Scler Frontotemporal Degener. 2013;14(2):127-131. doi:10.3109/ 17482968.2012.729595

248. Simon NG, Kiernan MC. Diaphragm ultrasound in amyotrophic lateral sclerosis and other neuromuscular disorders. Clin Neurophysiol. 2016;127(1):28-30. doi:10.1016/j. clinph.2015.04.066

249. Oudeman J, Eftimov F, Strijkers GJ, et al. Diagnostic accuracy of MRI and ultrasound in chronic immune-mediated neuropathies. Neurology. 2020;94(1):e62-e74. doi:10.1212 wnl.0000000000008697

250. Regensburger AP, Wagner AL, Hanslik G, et al. Ultra-highfrequency ultrasound in patients with spinal muscular atrophy: a retrospective feasibility study. Muscle Nerve. 2020;61(3):E18e21. doi:10.1002/mus.26796
251. Wu JS, Darras BT, Rutkove SB. Assessing spinal muscular atrophy with quantitative ultrasound. Neurology. 2010;75 (6):526-531. doi:10.1212/WNL.0b013e3181 eccf8f

252. Hobson-Webb LD, Massey JM, Juel VC, Sanders DB. The ultrasonographic wrist-to-forearm median nerve area ratio in carpal tunnel syndrome. Clin Neurophysiol. 2008;119(6):1353-1357. doi:10.1016/j.clinph.2008.01.101

253. Cartwright MS, White DL, Demar S, et al. Median nerve changes following steroid injection for carpal tunnel syndrome. Muscle Nerve. 2011;44(1):25-29. doi:10.1002/mus.22067

254. Sernik RA, Abicalaf CA, Pimentel BF, Braga-Baiak A, Braga L, Cerri GG. Ultrasound features of carpal tunnel syndrome: a prospective case-control study. Skeletal Radiol. 2008;37 (1):49-53. doi:10.1007/s00256-007-0372-9

255. Wijntjes J, Borchert A, van Alfen N. Nerve ultrasound in traumatic and iatrogenic peripheral nerve injury. Diagnostics. 2021;11 (1):30. doi:10.3390/diagnostics11010030

256. Ghajarzadeh M, Dadgostar M, Sarraf P, Emami-Razavi SZ, Miri S, Malek M. Application of ultrasound elastography for determining carpal tunnel syndrome severity. Jpn J Radiol. 2015;33(5):273-278. doi:10.1007/s11604-015-0416-3

257. Kantarci F, Ustabasioglu FE, Delil S, et al. Median nerve stiffness measurement by shear wave elastography: a potential sonographic method in the diagnosis of carpal tunnel syndrome. Eur Radiol. 2014;24(2):434-440. doi:10.1007/s00330-013-3023-7

258. Orman G, Ozben S, Huseyinoglu N, Duymus M, Orman KG. Ultrasound elastographic evaluation in the diagnosis of carpal tunnel syndrome: initial findings. Ultrasound Med Biol. 2013;39 (7):1184-1189. doi:10.1016/j.ultrasmedbio.2013.02.016

259. Paluch L, Pietruski P, Walecki J, Noszczyk BH. Wrist to forearm ratio as a median nerve shear wave elastography test in carpal tunnel syndrome diagnosis. J Plast Reconstr Aesthet Surg. 2018;71(8):1146-1152. doi:10.1016/j.bjps.2018.03.022

260. Zhang C, Li M, Jiang J, et al. Diagnostic Value of virtual touch tissue imaging quantification for evaluating median nerve stiffness in carpal tunnel syndrome. J Ultrasound Med. 2017;36 (9):1783-1791. doi:10.1002/jum.14213

261. Tatar IG, Kurt A, Yavasoglu NG, Hekimoglu B. Carpal tunnel syndrome: elastosonographic strain ratio and cross-sectional area evaluation for the diagnosis and disease severity. Med Ultrason. 2016;18(3):305-311. doi:10.11152/mu.2013.2066.183.tat

262. Nakamichi K, Tachibana S. Restricted motion of the median nerve in carpal tunnel syndrome. J Hand Surg Br. 1995;20 (4):460-464. doi:10.1016/s0266-7681(05)80153-6

263. Hough AD, Moore AP, Jones MP. Reduced longitudinal excursion of the median nerve in carpal tunnel syndrome. Arch Phys Med Rehabil. 2007;88(5):569-576. doi:10.1016/j.apmr.2007.02.015

264. Walker FO, Cartwright MS, Blocker JN, et al. Prevalence of bifid median nerves and persistent median arteries and their association with carpal tunnel syndrome in a sample of Latino poultry processors and other manual workers. Muscle Nerve. 2013;48 (4):539-544. doi:10.1002/mus.23797

265. Cartwright MS, Walker FO, Newman JC, et al. Muscle intrusion as a potential cause of carpal tunnel syndrome. Muscle Nerve. 2014;50(4):517-522. doi:10.1002/mus.24183

266. Yoon JS, Walker FO, Cartwright MS. Ultrasonographic swelling ratio in the diagnosis of ulnar neuropathy at the elbow. Muscle Nerve. 2008;38(4):1231-1235. doi:10.1002/mus.21094

267. Paluch L, Noszczyk B, Nitek Ż, Walecki J, Osiak K, Pietruski P. Shear-wave elastography: a new potential method to diagnose ulnar neuropathy at the elbow. Eur Radiol. 2018;28 (12):4932-4939. doi:10.1007/s00330-018-5517-9

268. Paluch L, Noszczyk BH, Walecki J, Osiak K, Kiciński M, Pietruski P. Shear-wave elastography in the diagnosis of ulnar tunnel syndrome. J Plast Reconstr Aesthet Surg. 2018;71 (11):1593-1599. doi:10.1016/j.bjps.2018.08.018 
269. Gruber H, Glodny B, Peer S. The validity of ultrasonographic assessment in cubital tunnel syndrome: the value of a cubital-tohumeral nerve area ratio (CHR) combined with morphologic features. Ultrasound Med Biol. 2010;36(3):376-382. doi:10.1016/j.ultrasmedbio.2009.09.008

270. Song S, Yoo Y, Won SJ, Park HJ, Rhee WI. Investigation of the diagnostic value of ultrasonography for radial neuropathy located at the spiral groove. Ann Rehabil Med. 2018;42(4):601-608. doi:10.5535/arm.2018.42.4.601

271. Kim JY, Song S, Park HJ, Rhee WI, Won SJ. Diagnostic cutoff value for ultrasonography of the common fibular neuropathy at the fibular head. Ann Rehabil Med. 2016;40(6):1057-1063. doi:10.5535/arm.2016.40.6.1057
272. Tawfik EA, El Zohiery AK, Abouelela AA. Proposed Sonographic Criteria for the Diagnosis of Idiopathic Tarsal Tunnel Syndrome. Arch Phys Med Rehabil. 2016;97 (7):1093-1099. doi:10.1016/j.apmr.2015.11.012

273. Fantino O, Bouysset M, Pialat JB. Can the axial cross-sectional area of the tibial nerve be used to diagnose tarsal tunnel syndrome? An ultrasonography study. Orthop Traumatol Surg Res. 2020;102630. doi:10.1016/j.otsr.2020.02.021

\section{Publish your work in this journal}

The International Journal of General Medicine is an international, peer-reviewed open-access journal that focuses on general and internal medicine, pathogenesis, epidemiology, diagnosis, monitoring and treatment protocols. The journal is characterized by the rapid reporting of reviews, original research and clinical studies across all disease areas. The manuscript management system is completely online and includes a very quick and fair peer-review system, which is all easy to use. Visit http://www.dovepress.com/ testimonials.php to read real quotes from published authors. 